\title{
Multialinhamento de seqüências biológicas utilizando algoritmos genéticos
}

\author{
Adriano Kiyoshi Oliveira Ogata
}

Prof. Dr. Alexandre Cláudio Botazzo Delbem

Dissertação apresentada ao Instituto de Ciências Matemáticas e de Computação - ICMC-USP, como parte dos requisitos para obtenção do título de Mestre em Ciências - Ciências de Computação e Matemática Computacional.

\section{"VERSÃO REVISADA APÓS A DEFESA"}

Data da Defesa:

$18 / 09 / 2006$

Visto do Orientador:

$$
\text { USP - São Carlos }
$$

Jan eiro/ 2007 

Multialinhamento de seqüências biológicas utilizando algoritmos genéticos 



\section{AGRADECIMENTOS}

Ao prof. Dr. Alexandre Cláudio Botazzo Delbem; a todos os professores; aos colegas e amigos feitos nesse período, especialmente Thaís e Glauco. A todos que contribuíram com este trabalho, direta ou indiretamente. Em especial à Sabrina. 


\section{RESUMO}

Dentro da bioinformática uma das atividades mais realizadas é o alinhamento de seqüências biológicas [1]. Seus resultados são utilizados em várias atividades que desdobram-se em áreas de pesquisa interdisciplinares com geração de diversos subprodutos. Sendo uma das primeiras etapas de tais tarefas, o multialinhamento é então importante para garantir a qualidade dos resultados obtidos em vários estudos do material genético. Para este trabalho espera-se a reprodução dos resultados já publicados na área [2]; [3]; [4]; [5]; [6]). A implementação de um programa de multialinhamento global de seqüências biológicas utilizando uma abordagem iterativa estocástica por algoritmo genético, uma forma relativamente recente [7] de se atacar tal problema. Obtenção de um panorama sobre as soluções alternativas existentes. 


\begin{abstract}
Multialignment of biological sequences is one of the most frequently used activities in bioinformatics. The results provided by sequence alignment are used in the solution of other bioinformatics problems.

Since a multialignment procedure is one of the first steps of many bioinformatics problems, the condition of an alignment affects the quality of the results obtained for these problems. Multialignment of biological sequences is a complex problem (NP complete) and requires usually heuristics to obtain acceptable performance. Evolutionary algorithms have been used with relevant results. This work aims to find better solutions for the multialignment problem using evolutionary computation. In order to achieve that, this research investigates techniques using evolutionary computation applied to multialignment problem and searches to reproduce their results. Moreover, the development of an approach that performs global multialignment of biological sequences using evolutionary algorithms and an evaluation of the available multialignment techniques are also proposed.
\end{abstract}

Keywords: Multialignment, Evolutionary Algorithms, Bioinformatics 


\section{Lista de Ilustrações}

Figura 1: A esquerda, representação do criacionismo e a direita, transformismo..................11

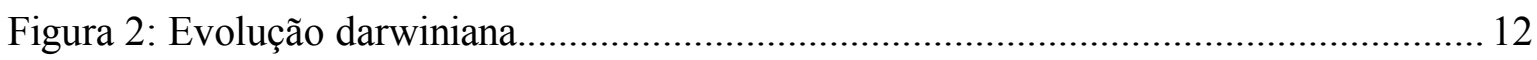

Figura 3: Mariposas em ambientes diversos. Em cada um dos três ambientes há duas mariposas: uma típica (clara) e outra melânica (escura).................................................... 15

Figura 4: Geração de gametas com ocorrência de crossover............................................. 18

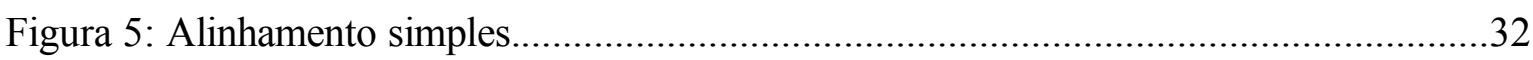

Figura 6: Desempenho da implementação do SAGA comparado com ClustalW .................. 48

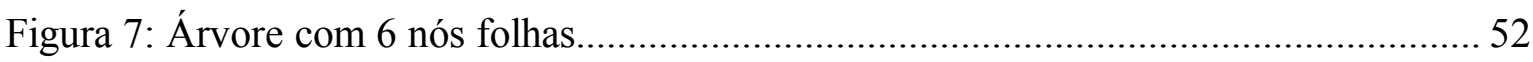

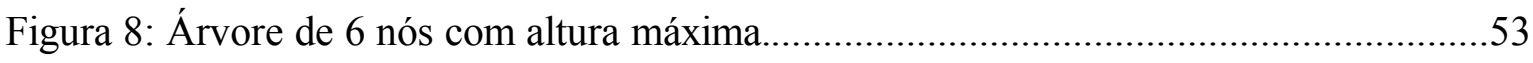

Figura 9: Desempenho da proposta de algoritmo progressivo com melhor árvore guia em

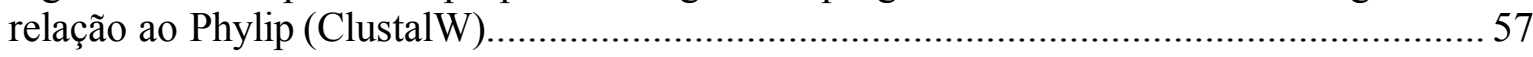

Figura 10: Remoção da sub-árvore de raiz 5 (em destaque) deixando nó 4 com grau 2......62

Figura 11: Inserção da sub-árvore de raiz 4 no nó destino 13 .............................................63 


\section{Sumário}

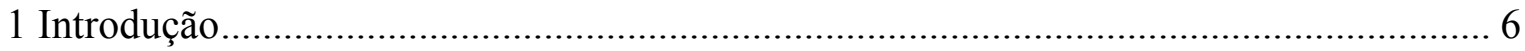

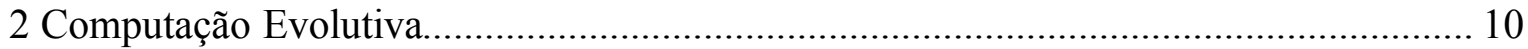

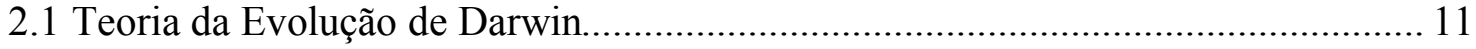

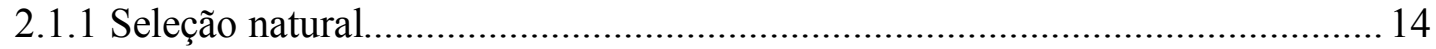

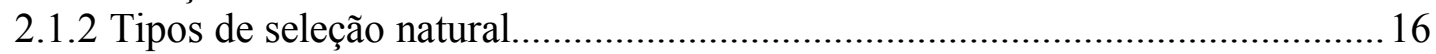

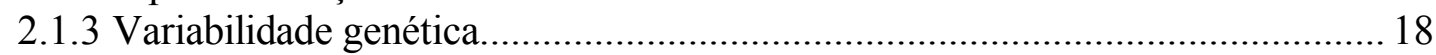

2.2 Algoritmos genéticos.................................................................................... 19

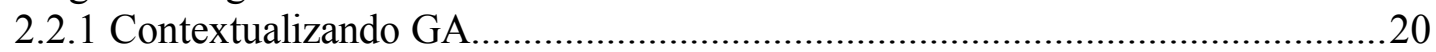

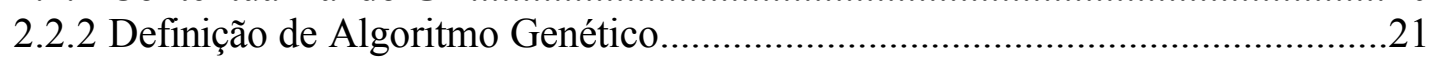

2.2.3 Algoritmo genético simples...........................................................................23

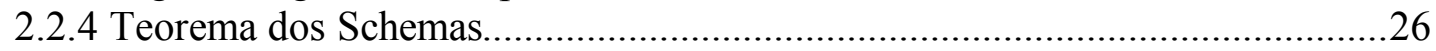

2.2.5 Paralelismo implícito............................................................................... 28

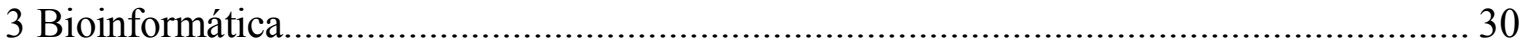

3.1 Alinhamentos em bioinformática...........................................................................

3.2 Multialinhamento de seqüências........................................................................... 33

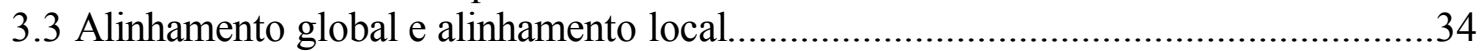

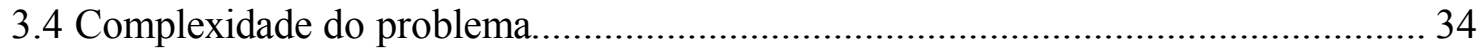

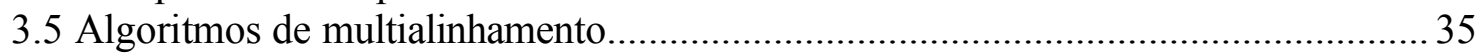

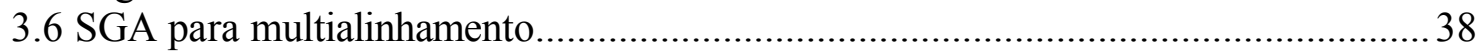

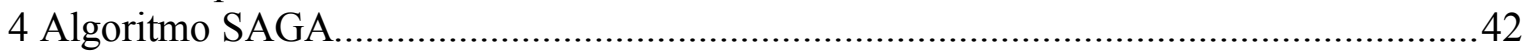

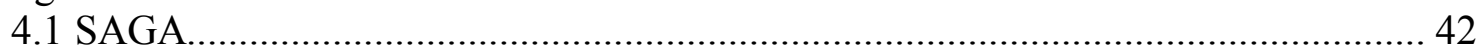

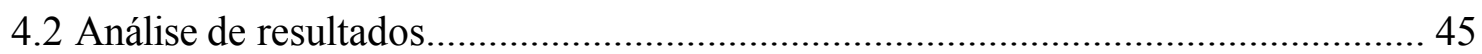

5 Busca por filogenias para multialinhamento............................................................... 49

5.1 Filogenias por algoritmo de busca exaustiva...........................................................51

5.2 Funcionamento do algoritmo.......................................................................... 51

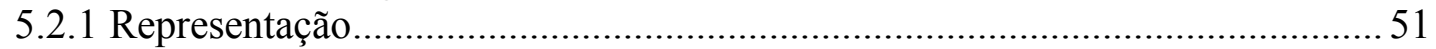

5.2.2 Geração das diferentes topologias.................................................................53

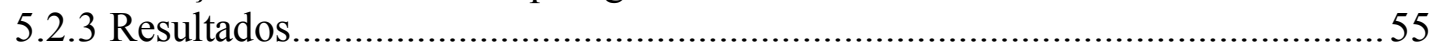

5.3 Filogenias por abordagem evolutiva de projeto de redes..........................................57

5.3.1 Algoritmos de projeto de redes......................................................................57

5.3.2 Representação nó-profundidade.....................................................................59

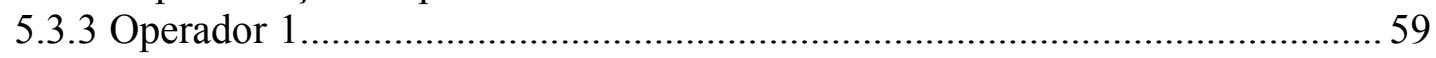

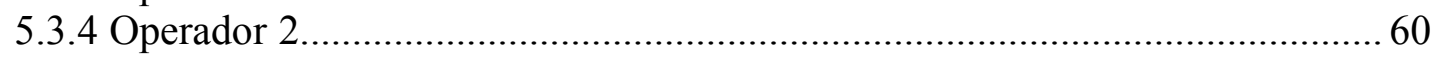

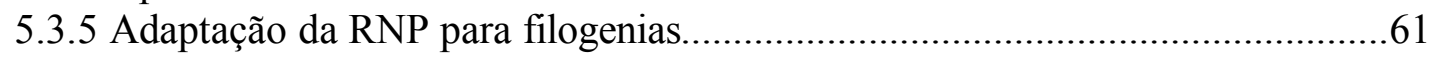

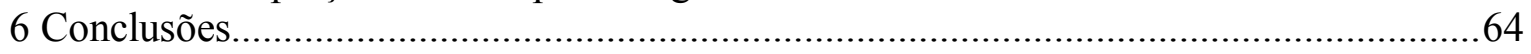

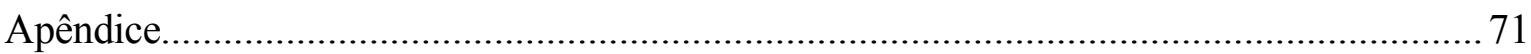

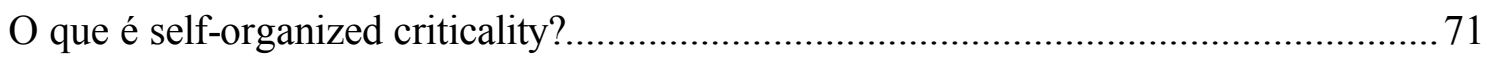

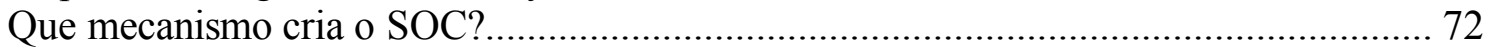

Qual a relação com um AE?..................................................................................72

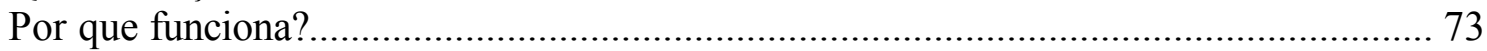

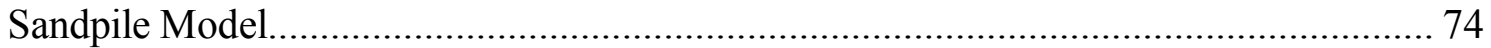

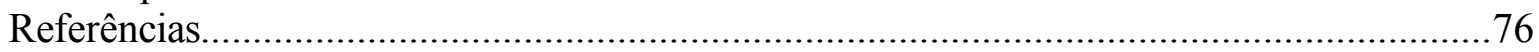




\section{INTRODUÇÃO}

Responsável pelo armazenamento do material genético, a molécula de $D N A$ (ácido desoxirribonucléico) teve sua estrutura descoberta por Watson e Crick [8]. A partir daí descobriu-se que havia uma transferência de informações: a seqüência de monômeros que constituíam a molécula de $D N A$ poderia ser utilizada, por organismos, na sintetização de proteínas. Com quatro diferentes tipos de unidades básicas (bases nitrogenadas representadas pelas letras $A, G, C$ e $T$ ) o $D N A$ pode ser inteiramente representado. Ao processo de determinação da seqüência de bases que compõem a molécula de $D N A$ dá-se o nome de seqüenciamento [9]. Por meio deste processo tornou-se possível armazenar as informações contidas no material genético de um organismo em mídia digital. Bancos de dados, tanto públicos quanto de iniciativa privada, foram criados para concentrar tais informações de maneira a permitir que os estudos progredissem mais rapidamente. Em questão de alguns anos, bilhões de seqüências foram determinadas e, com o uso dos seqüenciadores automáticos, houve um aumento muito grande no volume de dados criados [10]. Gerenciá-los, bem como interpretá-los, tornou-se a incumbência de uma área de pesquisa denominada bioinformática. Extrair conhecimento de dados biológicos utilizando abordagens computacional e informacional é uma possível definição [7] para esta área interdisciplinar, que pode unir diversas áreas, tais como matemática, estatística, ciência da computação, biologia molecular e física.

\subsection{Motivação}

Paralelo ao seqüenciamento do genoma de uma espécie é necessária a análise da massa de dados obtida. Dentre algumas destas atividades de análise, pode-se citar: predição da estrutura espacial de proteínas, estudo da homologia entre famílias conhecidas de 
seqüências e novas amostras, sugestão de iniciadores (primers) para o PCR (polymerase chain reaction) e estudo de reconstrução de árvores filogenéticas [7]. Para realização dessas atividades é necessário que várias seqüências sejam alinhadas, processo esse chamado de multialinhamento de seqüências.

\subsection{Multialinhamento}

As técnicas utilizadas na bioinformática para atacar este problema são algoritmos de otimização, que podem ser divididos em três categorias [7]: exatos, progressivos e iterativos. Os alinhamentos que utilizam estas técnicas são comentados a seguir.

Alinhamentos exatos utilizam programação dinâmica para encontrar o alinhamento ótimo de um pequeno conjunto de seqüências. A demanda por recursos computacionais (quantidade de memória e tempo de processamento) cresce rapidamente conforme aumenta o número de seqüências, o que torna sua aplicação restrita ([7];[1]).

O alinhamento progressivo escolhe, dentre um conjunto de seqüências a serem alinhadas, apenas um par, alinhando-o por meio da programação dinâmica. A este resultado parcial adiciona-se progressivamente as demais seqüências, uma a uma, utilizando programação dinâmica em cada alinhamento. Este é um dos métodos mais utilizados atualmente [1] sendo os programas Clustal e ClustalW uma das implementações mais difundidas desta classe de alinhamento. Dentre as vantagens deste método é destacado a velocidade e simplicidade do código [7]. Algumas desvantagens, apontadas por [1], são a dependência do primeiro par alinhado (quanto maior a similaridade entre estas seqüências iniciais, melhor o alinhamento final) e a escolha da matriz de pontuação das proteínas. Matrizes de pontuações inadequadas podem gerar resultados insatisfatórios, deixando a tarefa de decisão a encargo do usuário, que pode desconhecer a relevância de sua decisão. 
Alinhamentos iterativos são realizados gerando-se uma solução inicial e buscando seu refinamento por meio de iterações onde o alinhamento inicial é gradualmente melhorado. Os ciclos de refinamento da solução permitem, por exemplo, que problemas como a dependência da similaridade no alinhamento inicial (caso do alinhamento progressivo) sejam minimizados à medida em que alinhamentos alternativos melhores são sempre procurados durante as iterações, ao contrário do alinhamento progressivo que pode ser comprometido quando duas seqüências pouco similares são escolhidas inicialmente [1]. Dependendo da abordagem utilizada no refinamento da resposta, os alinhamentos iterativos podem ser classificados em determinísticos ou estocásticos sendo os primeiros os mais simples. Segundo Mount [1], abordagens iterativas estocásticas utilizam métodos como o treinamento de HMM (Hidden Markov Model), simulated annealing e computação evolutiva (algoritmos genéticos e programação genética).

\subsection{Objetivo}

Alinhamentos múltiplos são problemas complexos [9] e quando comparados com problemas de alinhamento simples observa-se uma explosão na demanda por recursos computacionais conforme aumentam a quantidade e o comprimento das amostras (tamanho das seqüências) analisadas. Resultados recentes utilizando algoritmos genéticos em multialinhamentos iterativos estocásticos apresentaram desempenho comparáveis aos de métodos tradicionais com mais de dez anos de desenvolvimento ([2]; [3]; [4]; [5]; [6]), com a vantagem de serem inerentemente paralelizáveis [11].

Este trabalho investiga os princípios fundamentais do algoritmo ClustalW e de Algoritmos Genéticos para resolver o problema de alinhamentos múltiplos. Primeiramente o Algoritmo Genético SAGA [6] foi implementado, buscando-se reproduzir os resultados da 
literatura e explorar potenciais melhorias. Verificou-se que os resultados do SAGA são difíceis de serem generalizados, reduzindo assim sua relevância para uso por pesquisadores da área biológica. $\mathrm{Na}$ investigação sobre os fundamentos do ClustalW, pôde-se avaliar o quão importante é a ordem dos pares de seqüências escolhidas para o alinhamento. Ordens adequadas podem ser obtidas com base em árvores filogenéticas das seqüências envolvidas.

Buscando explorar este aspecto do múltiplo alinhamento progressivo, duas abordagens para geração de árvores filogenéticas mais adequadas para aumentar a qualidade dos alinhamentos obtidos foram exploradas neste trabalho. A primeira proposta encontra novas árvores com base em uma busca exaustiva. Os resultados mostram que a nova abordagem produz resultados sempre similares ou superiores ao do ClustalW. A segunda abordagem proposta busca reduzir o tempo de computação em relação à busca exaustiva para se encontrar filogenias mais adequadas para guiar o processo de alinhamento. Esta abordagem é baseada em Algoritmos Evolutivos para Projeto Redes [35] adaptados para redes que correspondem a árvores filogenéticas. Este trabalho mostra como pode-se utilizar esta técnica para geração de filogenias, buscando motivar a intensificação de pesquisas com foco em exploração de filogenias para alinhamento múltiplos. A implementação desta proposição é relativamente elaborada. Assim, sua implementação e a validação das qualidades das árvores geradas são tarefas para trabalhos futuros.

\subsection{Organização}

Os demais Capítulos da dissertação estão organizados como descrito a seguir. O Capítulo 2 introduz os conceitos de evolução e os algoritmos genéticos. O Capítulo 3 apresenta a área de bioinformática, o problema de múltiplos alinhamentos e os principais algoritmos para alinhamento de seqüências. O Capítulo 4 mostra o algoritmo SAGA e a 
10

performance desta abordagem. O Capítulo 5 propõe estratégias de investigação por melhores árvores filogenéticas para guiar alinhamentos múltiplos progressivos. Por fim, o Capítulo 6 destaca os principais aspectos descobertos com a investigação realizada neste trabalho bem como, sugere novas pesquisas a partir dos resultados obtidos. 


\section{COMPUTAÇÃO EVOLUTIVA}

Os algoritmos genéticos fazem parte do que é denominado computação evolutiva [7]. Baseado na teoria da evolução, a computação evolutiva busca imitar a dinâmica das populações de indivíduos que competem entre si pela sobrevivência, inspirado na teoria da evolução de Darwin.

Os algoritmos evolutivos, como são chamadas as técnicas baseadas em computação evolutiva, são divididos em três grandes grupos de investigação [12]: algoritmos genéticos (AG), estratégias evolutivas e programação evolutiva. Tais métodos possuem em comum uma população de possíveis soluções, representadas por indivíduos. Este indivíduos sofrem mudanças aleatórias e a manutenção dessa população é feita pelo método chamado de seleção.

De forma a estabelecer adequadamente os princípios da computação evolutiva é apresentado a seguir uma revisão sobre a Teoria da Evolução, que serviu como inspiração para os algoritmos genéticos. Os conceitos apresentados nesta revisão serão utilizados ao longo deste trabalho.

O primeiro conceito abordado é o de evolução: fenômeno onde o meio ambiente ajusta a população segundo o nível de adaptação de cada organismo a este meio. O mecanismo de funcionamento de um algoritmo genético é baseado neste fenômeno. O segundo conceito apresenta os tipos de seleção natural. A estratégia de seleção de indivíduos em um algoritmo genético se vale de técnicas que podem ser vistas como análogas aos tipos de seleção natural. Por fim, o terceiro conceito é o de variabilidade genética, necessário para uma melhor exploração do espaço de busca o que pode evitar, por exemplo, convergências prematuras para ótimos locais.

Os conceitos básicos utilizados nos algoritmos genéticos são simples. Entretanto estes 
muitas vezes não são precisamente definidos. A seção seguinte procura então esclarecê-los.

\subsection{Teoria da Evolução de Darwin}

Em meados do século XIX, uma das explicações aceitas sobre a origem das espécies foi o criacionismo [13]. Segundo esta teoria todos os organismos teriam sido criados tal qual existem atualmente sem terem sofrido qualquer tipo de alteração ou evolução. Outra teoria da época foi a evolução segundo Lamarck, chamada de transformismo, segundo a qual os organismos evoluiriam por meio da herança de características adquiridas ao longo de suas vidas, não existindo ancestrabilidade comum ou extinção de espécies. Assim, características adquiridas por um indivíduo seriam passadas aos seus descendentes.

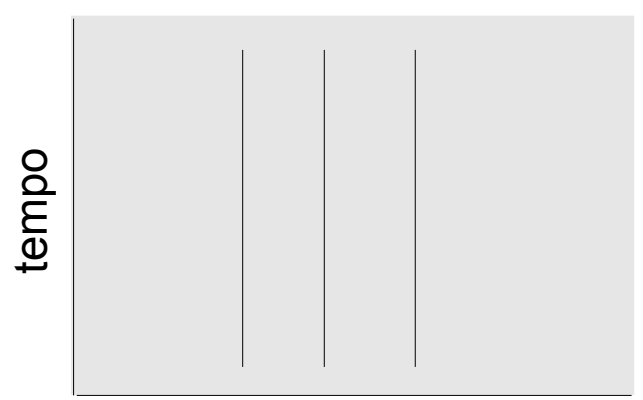

Formação de espécies

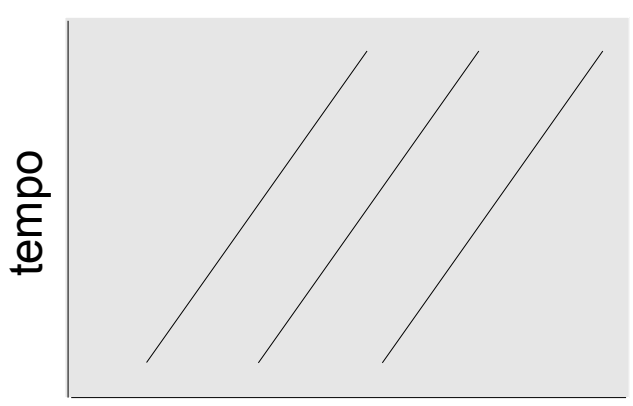

Formação de espécies

Figura 1: A esquerda, representação do criacionismo e a direita, transformismo.

Na Figura 1 temos a representação gráfica destas duas teorias. Nos gráficos, as linhas representam diferentes espécies e seu comportamento no decorrer do tempo. Inclinações das linhas indicam evolução na espécie. No criacionismo (gráfico à esquerda) as espécies não sofrem nenhum tipo de evolução. Não há nem extinção (nenhuma linha foi interrompida antes de alcançar o topo da ordenada) nem criação de novas espécies (espécies são criadas apenas num momento inicial). No gráfico à direita, a diferença evidente está na inclinação das retas, indicando a mudança nos organismos. Assim como no caso anterior, nenhuma 
espécie foi criada ou extinta no gráfico.

Darwin revolucionou o pensamento científico de sua época ao propor a teoria da seleção natural por meio da qual explicou a dinâmica dos organismos vivos. Segundo esta teoria os indivíduos seriam selecionados pelo próprio meio ambiente. Em uma dada população, certos indivíduos tenderiam a contribuir com um número maior de descendentes que os outros. Sendo a prole semelhante aos progenitores, pode-se supor que um ou mais atributos que causavam esta vantagem estariam sendo transmitidas aos descendentes. Haveria então uma mudança na composição da população. Apenas os que apresentassem uma adaptabilidade mínima teriam chances maiores de sobrevivência. Em outras palavras, indivíduos, ou mesmo espécies, que não se mostrassem minimamente adaptadas ao meio seriam extintos, enquanto os mais bem adaptados sobreviveriam. Ainda segundo Darwin, haveria um ancestral comum a todas as espécies, existentes ou extintas. Sob efeito de um longo período de tempo este ancestral teria evoluído gerando assim as espécies, que ainda estariam evoluindo. Este pensamento contrariava tanto o criacionismo (ao propor a evolução das espécies) quanto o transformismo (ao sugerir a existência de um ancestral comum).

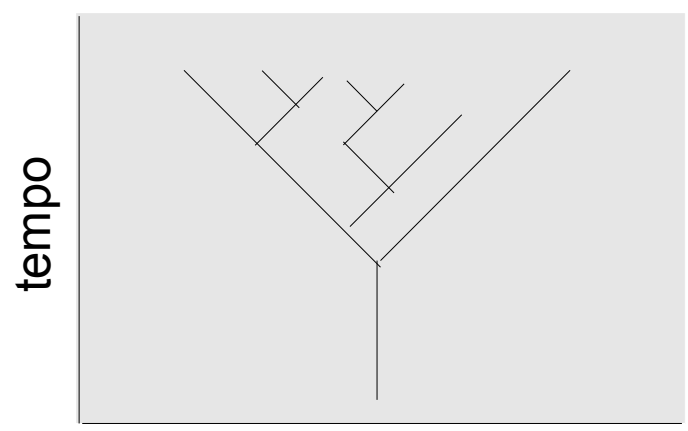

Formação de espécies

Figura 2: Evolução darwiniana. 
Na Figura 2, que segue o mesmo padrão da figura anterior, temos a evolução darwiniana. As espécies evoluem (retas inclinadas) e algumas são criadas (bifurcações) e extintas (segmentos que não atingem o topo do gráfico). Um ancestral comum é a origem de todas as espécies.

Entretanto tal teoria não foi aceita na íntegra. Apesar da aceitação do seu modelo de evolução (a seleção natural), Darwin foi incapaz de explicar os mecanismos pelos quais essa adaptação ocorria, conceito necessário para se entender a seleção natural. Qual a origem da variabilidade e diversidade de características presentes nas espécies? Como estas características eram transmitidas no decorrer das gerações, ou seja, do progenitor para a prole? Estas questões, além de uma descrição do mecanismo de transferência de características dos seres vivos, não puderam ser respondidas por Darwin.

O conceito de hereditariedade, proposto por Mendel em 1865 [14] mas aceito apenas por volta de 1920, era a explicação que completava os estudos de Darwin e foi, também, a base de toda a genética moderna. Mendel explicou o modo como as características de um indivíduo poderiam ser transmitidas aos seus descendentes, ou seja, a hereditariedade. Segundo seu trabalho, haveria uma unidade mínima portadora das informações características de um ser vivo, mais tarde denominadas genes. Estes genes não se misturavam no decorrer das gerações. Isso fazia sentido pois se houvesse fusão destas características, com o passar das gerações aconteceria uma homogeinização de forma a diminuir a variabilidade de características na população. Como a natureza possui uma diversidade muito grande, como bem atestou Darwin em suas viagens [15], então realmente os genes pareciam não se misturar, corroborando com a hereditariedade de Mendel. Ao se preservar estes genes durante os cruzamentos, era possível que caracteres se mantivessem 
latentes, voltando a tornar-se perceptíveis sob certas circunstâncias. Isso garantiria a variabilidade das espécies.

Segundo Ridley, denomina-se neo-darwinismo, ou síntese moderna, a união da teoria da evolução pela seleção natural com a teoria de hereditariedade. As disputas entre cientistas, que tomavam partidos opostos na teoria da evolução, foram encerradas com esta união que proporcionou um sólido embasamento para a Teoria de Evolução de Darwin.

\subsubsection{Seleção natural}

Os seguintes fatores são necessários (mas não suficientes) para que aconteça a seleção natural:

- reprodução

- hereditariedade

- variação nas características

A existência desses fatores e a ocorrência da seleção natural podem ser ilustrados com um exemplo ocorrido na Inglaterra [13]. Neste país há variedades de mariposas da espécie Biston betularia que se diferem pela coloração que assume tons de cinza. Em um ambiente sem poluição, como era a Inglaterra antes da revolução industrial, as mariposas claras, chamadas de típicas, eram mais numerosas. Uma possível explicação seria que fossem melhor adaptadas uma vez que sua coloração serviria como camuflagem. Quando pousadas em troncos de carvalhos cobertos por líquens (uma simbiose entre algas e fungos), teriam menores chances de serem percebidas por predadores pois a coloração dos líquens era semelhante à dessas mariposas. Entretanto, com a poluição decorrente das indústrias no período revolução industrial, os líquens desapareceram dos troncos das árvores, que passaram a apresentar coloração mais escura. Com isso, a vantagem passou para as 
mariposas mais escuras e mudou a proporção observada. Em outras palavras, estas mariposas mais escuras, ditas melânicas, tornaram-se mais numerosas que as típicas.

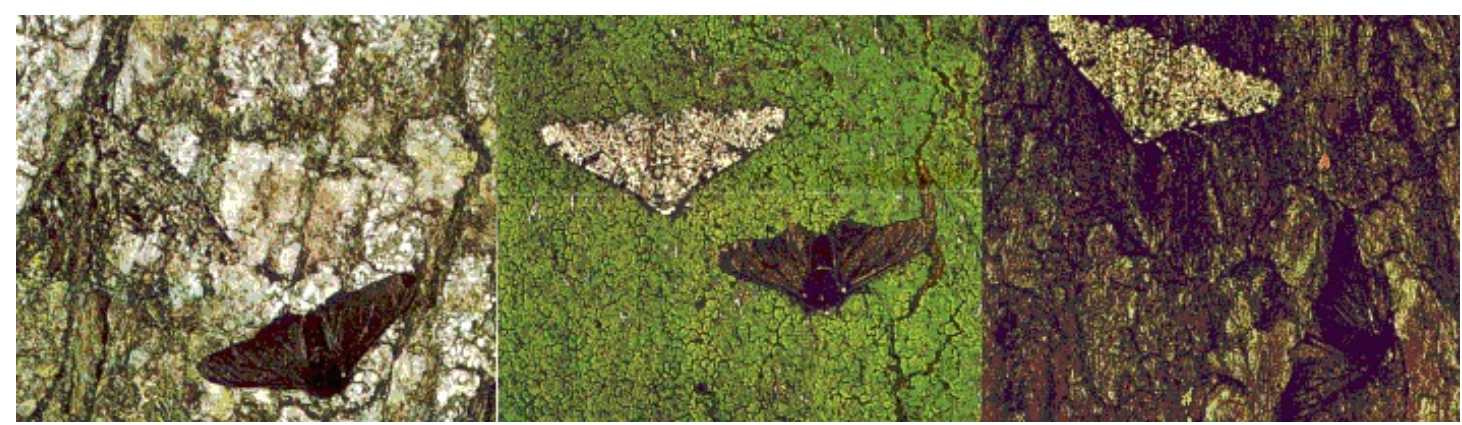

Figura 3: Mariposas em ambientes diversos. Em cada um dos três ambientes há duas mariposas: uma típica (clara) e outra melânica (escura).

Na figura 3 há duas mariposas em três diferentes troncos de árvore. A esquerda um tronco de carvalho da zona rural. Nesta situação é difícil perceber a mariposa típica enquanto a melânica é facilmente reconhecida, sendo um alvo fácil para predadores. $\mathrm{Na}$ imagem do meio o carvalho está coberto por musgo verde tornando evidente as duas mariposas. Na última imagem um outro carvalho, agora de uma região industrial, dá vantagem à camuflagem da mariposa melânica.

Neste exemplo percebe-se os três fatores que permitem que a seleção natural ocorra. Mariposa é um exemplo de espécie onde seus indivíduos se reproduzem gerando descendentes que trazem características herdadas dos pais. Possuem variabilidade em suas características. Desta forma demonstrou-se, por meio de um dos mais clássicos exemplos nos estudos de evolução, que a seleção natural pode ajustar a freqüência das mariposas típicas e melânicas e modifica seu perfil populacional [13].

Por outro lado, em ambientes constantes onde uma população de indivíduos com o mesmo nível de adaptabilidade (fitness), a seleção natural pode não acontecer. Em uma estufa com ambiente rigorosamente controlado, livre de pragas e sem escassez de recursos, 
populações ideais de plantas geradas por clonagem possuem uma mesma aptidão. Em outras palavras, não há diferença entre os indivíduos da população e todos sobrevivem (pois não há escassez de recursos). Dessa forma, a seleção deixa de atuar uma vez que a população está homogênea e o meio constante. A população possui os fatores reprodução e hereditariedade mas falta o fator variabilidade. Se esta população fosse devolvida à natureza, sob ação de fatores ambientais (pragas, competição, escassez de recursos etc), bastaria um único fator desfavorável (como uma doença) para extinguir toda a população.

\subsubsection{Tipos de seleção natural}

Ridley classifica em três os tipos de seleção natural de acordo com os efeitos sobre uma determinada característica. Para exemplificar será usado o tamanho do corpo como característica estudada.

Em um determinado ambiente indivíduos com corpo pequeno deixam mais descendentes que seus concorrentes de corpo mais avantajado. Se a aptidão dos indivíduos com corpo pequeno for maior e se tal característica for hereditária, a seleção irá causar uma diminuição no tamanho médio da população. Se, por outro lado, indivíduos com tamanho maior fossem os privilegiados, analogamente o tamanho médio da população iria aumentar. Este tipo de seleção é chamada de direcional. Um exemplo desse tipo de seleção aconteceu com os salmões. Salmões grandes eram mais procurados de forma que a chance dos pequenos sobreviverem foi aumentada. Essa prática causou a diminuição do tamanho médio da população deste peixe no decorrer dos anos [13].

No caso onde indivíduos com um perfil próximo à média populacional obtêm uma maior aptidão, fica caracterizada uma seleção do tipo estabilizadora. Assim, indivíduos com um corpo de tamanho médio seriam mais comuns que os maiores ou menores. Dessa forma, o 
efeito da seleção estabilizadora é o de manter a característica constante, no caso o tamanho do corpo. Um exemplo é o tamanho do corpo dos recém-nascidos humanos. Bebês muito grandes eram pouco comuns por danos tanto à mãe quanto ao recém-nascido durante o parto; enquanto bebês muito pequenos naturalmente resistem menos ao parto. Isso tornou o tamanho dos bebês constante (seleção estabilizadora) até o ponto onde a medicina avançou o suficiente para permitir que tanto os grandes quanto os pequenos bebês sobrevivessem ao parto (seja por parto cesariano, para os maiores, ou auxiliados por incubadoras, no caso dos menores). Com esta mudança deixa de haver uma relação entre o tamanho do corpo e a taxa de sobrevivência de forma que a seleção deixa de atuar.

O último tipo de seleção age de forma oposta à seleção estabilizadora e recebe o nome de seleção disruptiva. Quando indivíduos com perfis diferentes da média da população, no exemplo, com tamanho de corpo maior ou menor que a média da população possuem chances maiores de sobrevivência então a seleção é dita disruptiva e seu efeito sobre a população é causar o aparecimento de grupos de indivíduos com características semelhantes. Haveriam então um grupo com tamanho de corpo acima da média e outro grupo com tamanho de corpo abaixo da média. Um exemplo dessa seleção ocorreu em um experimento onde drosófilas (tipo de mosca) com uma quantidade de pêlos considerada intermediária em certa região do corpo foram impedidas de procriar [13]. Em algumas gerações o que houve foi a divergência da população: o número de indivíduos com uma quantidade de pêlos intermediária havia caído drasticamente, sendo a população dominada por moscas tanto com muito quanto com poucos pêlos.

$\mathrm{Na}$ ausência de seleção o que acontece é uma desvinculação entre a característica estudada e a aptidão. Em outras palavras, não importa qual característica o indivíduo 
apresente a aptidão não é influenciada. Nestes casos, a população, com relação a característica estudada, não apresenta qualquer variação no decorrer das gerações.

\subsubsection{Variabilidade genética}

Dois mecanismos relacionados à variação genética são a recombinação (crossover) e a mutação.

Organismos diplóides são aqueles que possuem duas cópias de cada cromossomo em suas células (células diplóides ou $2 n$ ), exceto nas células com fins reprodutivos, os chamados gametas (células haplóides ou $n$ ), que possuem apenas uma cópia de cada cromossomo [14]. Resumindo, no organismo de um indivíduo, todas as células são diplóides, exceto os gametas. Por exemplo, o ser humano possui 23 pares de cromossomos. Para gerar gametas é preciso que o número de cromossomos seja reduzido à metade, ou seja, de uma célula $2 n$ gera-se células $n$, num processo conhecido por meiose. Isso é essencial para que se mantenha constante a quantidade de cromossomos da espécie uma vez que, da fusão de dois gametas (masculino e feminino) forma-se um indivíduo $2 n$.

Durante a geração do gameta pode acontecer do conteúdo de cada uma das duas cópias de um dado cromossomo ter seu material genético misturado. Este processo é chamado de crossover e é um dos fatores responsáveis pela variabilidade genética.

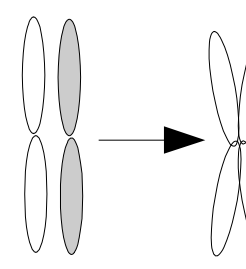

(a)

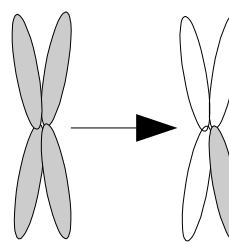

(b)

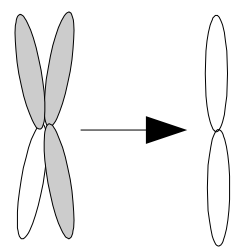

(c)

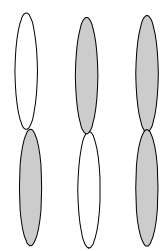

(d)

Figura 4: Geração de gametas com ocorrência de crossover. 
A Figura 4 ilustra isso. Em (a) há um dos pares de cromossomos de uma célula diplóide. Em (b) os cromossomos são preparados para a meiose. Em (c) ocorre crossover, ou seja, parte dos cromossomos se misturam. Em (d) os gametas são gerados. No caso onde o crossover não acontece, o número de gametas diferentes cai pela metade em relação ao apresentado. Fica claro a importância do crossover ao aumentar o número de gametas distintos e, conseqüentemente, variabilidade de indivíduos. Vale lembrar que a ocorrência desse fenômeno é aleatória.

Também aleatório é o fenômeno da mutação. Pode ocorrer no processo de duplicação dos cromossomos por meio de falhas durante a cópia do material genético. Esta variabilidade pode ser deletéria, vantajosa ou neutra. A seleção natural é quem classifica as mutações, de acordo com o ambiente em que o indivíduo está inserido. Caso a mudança provocada pela mutação cause uma melhora na aptidão do indivíduo, esta é classificada como vantajosa. Caso o prejudique, é chamada de deletéria. A mutação neutra ocorre quando não se percebe qualquer mudança na aptidão.

\subsection{Algoritmos genéticos}

Criado por Holland na década de 1960 e desenvolvido com a ajuda de seus alunos, os algoritmos genéticos (AG) tinham por objetivo inicial o estudo da adaptação do modo como ocorre na natureza com o objetivo de importar tais soluções para sistemas computacionais [16]. Goldberg contribuiu para a difusão dos AGs ao definir o algoritmo genético simples (simple genetic algorithm, sga). Este algoritmo tem servido como denominador comum na comparação de implementações que utilizam algoritmos genéticos. 


\subsubsection{Contextualizando GA}

Algoritmos genéticos pertencem ao paradigma genético que por sua vez fazem parte do Aprendizado de Máquina [17].

Por realizar uma busca em uma população de soluções, algoritmos genéticos também são vistos como funções de busca. [16] aponta três tipos de métodos tradicionais de busca:

1. Busca por dados armazenados. Como exemplo tem-se a recuperação de informações em um banco de dados.

2. Busca por caminhos que levam a um objetivo. Diz respeito a recuperar de forma eficiente um conjunto de estados que levam um sistema de seu estado inicial até o estado objetivo.

3. Busca por soluções. É a mais geral das formas de busca. O objetivo procurado é uma solução em um espaço normalmente amplo de soluções candidatas. Este tipo de busca envolve problemas que não podem ser descritos por seqüências de passos, como nos casos anteriores.

Sendo inviável uma enumeração de todas as possíveis soluções, nos casos de espaços de busca amplos, faz-se necessário examinar apenas uma parcela mínima de todo o espaço e conseguir com apenas estas poucas uma solução. Neste contexto os AGs têm sido largamente explorados e apresentado resultados relevantes [7].

Os algoritmos genéticos são também considerados formas de busca de propósito geral que, combinando características estocásticas e diretas, oferecem um equilíbrio entre exploração e pesquisa do espaço de busca [18]. Como exemplos de métodos que não possuem esse equilíbrio pode-se citar o hillclimbing e a busca aleatória [19]. O primeiro explora as melhores soluções em detrimento da pesquisa do espaço. $\mathrm{O}$ último executa uma 
pesquisa do espaço mas não explora as regiões promissoras encontradas.

\subsubsection{Definição de Algoritmo Genético}

Segundo Goldberg, algoritmos genéticos são algoritmos de busca inspirados em mecanismos da seleção natural e da genética. A solução do problema é codificada em uma estrutura de dados, usualmente um vetor de bits, chamada de cromossomo. Vários destes cromossomos coexistem em um conjunto denominado população. Assim uma população de cromossomos nada mais é que um conjunto de possíveis soluções. Esta população é criada, no início da execução do algoritmo, e mantida ao longo de várias iterações onde acontece uma sucessão de eventos semelhantes ao que ocorre na natureza.

Os algoritmos genéticos se valem de funções aleatórias para seu funcionamento, entretanto como observam ([19]; [16]; [18]), diferem das buscas aleatórias (random walks) uma vez que regiões do espaço de busca que se mostram mais promissoras são melhor exploradas.

As três propriedades necessárias para que ocorra a seleção natural, explicadas anteriormente, são simuladas nos algoritmos genéticos, visando um comportamento similar ao que ocorre em populações naturais: que os indivíduos melhor adaptados sobrevivam. No caso do algoritmo genético, sendo cada indivíduo da população uma solução, ao término de um determinado período de tempo, as soluções melhor adaptadas estariam na população.

Segundo Gen e Cheng, os algoritmos genéticos diferem dos métodos tradicionais de busca por manterem uma população de soluções potenciais. Métodos tradicionais geram uma seqüência de passos com os quais a solução é deterministicamente encontrada. Muitos deles utilizam informações adicionais, como derivadas e gradientes, para guiar a busca pontual pelo espaço de busca. Os algoritmo genéticos, por se valerem de vários pontos de 
busca, são menos susceptíveis a ótimos locais ao contrário dos métodos tradicionais, que ali podem ficar presos [20].

Durante a execução do algoritmo genético um ciclo de operações acontece de forma a simular os efeitos da seleção natural, inspirado na teoria de evolução de Darwin, nesta população de soluções potenciais. Indivíduos classificados como "melhores" possuem uma chance maior de sobrevivência, enquanto aqueles ditos "piores" têm suas chances reduzidas. Parte da população é selecionada e, aos pares, seus conteúdos são combinados de forma a gerar novos integrantes de população que possam vir a possuir alguma semelhança com estes que agiram como seus progenitores.

Para que a seleção natural aconteça, são necessários 3 fatores já explicados anteriormente: reprodução, hereditariedade e variação das características. Dessa forma o algoritmo genético deve satisfazer estes requisitos permitindo que a seleção natural, ou um simulação desta, aconteça.

Os indivíduos da população são criados através de reprodução, com exceção da primeira geração, que é gerada aleatoriamente. O primeiro quesito é portanto satisfeito.

Por serem resultado de uma combinação dos conteúdos dos progenitores, os indivíduos possuem semelhanças com estes no conteúdo que carregam. Assim parte das informações são transferidas dos pais aos descendentes, caracterizando a hereditariedade.

A variação das características acontece justamente nessa combinação dos conteúdos. Pelo fato das informações dos pais serem combinadas, e não copiadas, aos seus descendentes, as características podem se juntar em padrões inéditos na população, causando a variação necessária.

É importante observar que apenas esses fatores não implicam em seleção natural, mas 
apenas permitem que esta possa acontecer.

A seguir discute-se o funcionamento de um algoritmo genético simples. Este será a base sobre a qual uma implementação mais elaborada será proposta de forma a se atacar o problema de multialinhamento de seqüências biológicas. Entender o funcionamento do algoritmo simples será suficiente para se discutir em linhas gerais a implementação sugerida ao final deste trabalho.

\subsubsection{Algoritmo genético simples}

O algoritmo genético simples (simple genetic algorithm - sga) foi descrito por [19] e desde então inúmeras variações [25] foram criadas adaptando a forma original aos problemas encontrados. Apenas o funcionamento do sga original será discutido.

Inicialmente a forma com que as soluções potenciais serão representadas deve ser definida. As variáveis de controle do problema, por exemplo, poderiam ser representadas por uma string binária de comprimento arbitrário dependente do problema. A esta string completa dá-se o nome de cromossomo e cada bit é chamado de gene. Esta população de $m$ soluções (strings binárias de comprimento $k$ ) é inicializada de forma aleatória onde cada gene tem a mesma probabilidade de assumir qualquer um dos dois símbolos (“0”, "I"). Esta etapa é chamada de inicialização.

Cada cromossomo é então avaliado, ou seja, a solução que ele carrega em forma de string binária é decodificada e transformada em um valor que reflete a qualidade desta resposta. Este valor é chamado de aptidão (fitness) e é armazenado no próprio cromossomo.

$\mathrm{Na}$ etapa seguinte é preciso selecionar alguns indivíduos que serão responsáveis por gerar os novos elementos. Esta seleção é feita atribuindo-se uma probabilidade a cada 
cromossomo. Esta probabilidade é proporcional à aptidão do cromossomo, mas também leva em consideração o desempenho dos demais elementos. Esta forma de seleção é chamada de método da roleta (roulette wheel). Para entender seu funcionamento, pode-se imaginar que aquelas proporções levantadas anteriormente são proporcionalmente espalhadas sobre a superfície de um disco circular (a roleta). Proporcionalmente pois indivíduos com um desempenho relativo maior receberão áreas maiores. A seleção é feita girando-se a roleta. Desta forma é possível se selecionar qualquer um dos indivíduos da população, mas aqueles com uma aptidão maior terão maiores chances de serem escolhidos. Os progenitores são dessa forma escolhidos.

Cada par de progenitores é usado para se gerar um novo indivíduo. Isto é feito combinando os genes de ambos em um novo cromossomo. Este processo é realizado por dois operadores genéticos: crossover e mutação.

O crossover utilizado por Goldberg é chamado de crossover de um ponto (single-point crossover). Um número aleatório $c$, variando de 1 a $k-1$ (onde $k$ é o tamanho do cromossomo) é gerado. Copiam-se os genes de um dos progenitores, $P 1$, do intervalo 1 até $c$. Os demais genes, $c+1$ até $k$ são copiados do outro progenitor $P 2$. Se o mesmo processo for aplicado, mas trocando de lugar $P 1$ por $P 2$, é possível se gerar um segundo indivíduo. Assim o resultado deste processo são dois novos elementos.

Durante estas cópias de genes há uma probabilidade de erro. Esta falha tem o nome de mutação e a probabilidade de que este operador seja utilizado é igual para todos os genes do cromossomo, e definido arbitrariamente. Em outras palavras, se o valor a ser copiado para o novo indivíduo, em um determinado momento, fosse o símbolo ' 1 ', a mutação iria copiar erroneamente o valor ' 0 ' em seu lugar. 
Estes dois operadores, crossover e mutação, são responsáveis pela variabilidade genética necessária à seleção. Combinando cromossomos e alterando de forma pontual seu conteúdo propiciam uma pesquisa do espaço de busca que é fundamental para a qualidade da solução encontrada ao término da execução do algoritmo.

Os novos indivíduos são gerados até que sua quantidade atinja a quantidade da população inicial, substituindo-a totalmente. O ciclo se encerra, retornando a etapa de avaliação da população.

O algoritmo é finalizado quando o número de gerações pré-estabelecido foi alcançado.

Segue o algoritmo genético simples na sua forma original [19]:

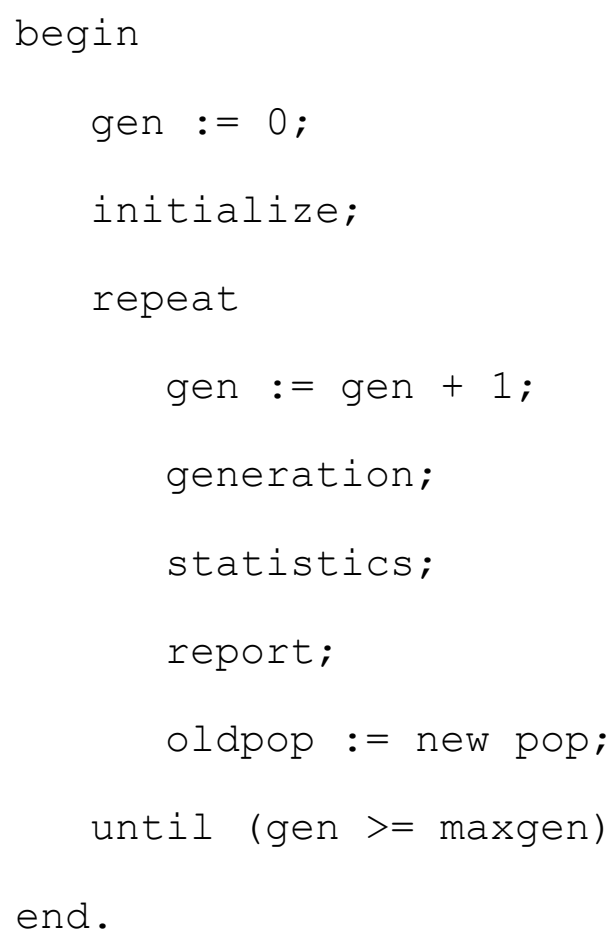

Os procedimentos "statistics" e "report" dizem respeito ao registro da evolução da população e a geração de um relatório, não comentados aqui. O procedimento "generation" é responsável pela seleção dos progenitores e pela aplicação dos operadores de crossover e mutação, explicados anteriormente. Os parâmetros dos procedimentos foram omitidos de 
forma a manter o código o mais simples possível sem afetar sua inteligibilidade.

\subsubsection{Teorema dos Schemas}

Uma das formas de se caracterizar matematicamente a evolução dos cromossomos é por meio do teorema dos schemas [20], desenvolvido por Holland [19]. A seguir são explicados os conceitos utilizados neste teorema, o efeito dos operadores genéticos, o enunciado do teorema e uma explicação sobre paralelismo implícito.

Schemas são padrões que descrevem um conjunto de strings binárias, as quais são informações formadoras do cromossomo. Em outras palavras, um schema representa um conjunto de cromossomos. Schemas utilizam um alfabeto de três símbolos: “0”, "l" e "\#” sendo este último um símbolo que substitui qualquer um dos dois símbolos anteriores.

De acordo com Mitchell [16], um schema pode ser visto como uma forma de se representar um conjunto de cromossomos que possuem em comum certa similaridade em determinadas posições de sua string binária. Isso acontece nas posições do schema que não são “\#” e que portanto são comuns a todos os elementos do conjunto.

Se um schema possui a propriedade de representar um conjunto de cromossomos, por sua vez, um cromossomo pode fazer parte de vários schemas.

Por exemplo, o cromossomo "0001" pertence aos schemas "000\#”, “00\#1" e "00\#\#", entre outros. Em contrapartida, o schema "000\#” representa o conjunto dos cromossomos “0000" e "0001".

A ordem do schema é igual ao número de posições determinadas, ou seja, com símbolos diferentes de “\#”. Quanto maior a ordem do schema, menor é o conjunto de cromossomos que este representa. Assim, o schema "000\#” possui ordem 3 pois três das suas quatro posições possuem símbolo diferente de “\#”. E o número de cromossomos representados é 
menor do que o de um schema com ordem menor, como por exemplo, “00\#\#”.

Usando destas propriedades, uma população de cromossomos pode ser vista tanto como um conjunto de schemas quanto um conjunto de representantes (instâncias) destes schemas.

O fato de um cromossomo pertencer a vários schemas permite que, ao se avaliar apenas um cromossomo, vários schemas sejam parcialmente inspecionados, que é um tipo de processamento em paralelo (vide Paralelismo Implícito a seguir).

Para um dado schema $s$ em um instante $t$, o teorema prevê o número de instâncias de $s$ esperadas em $t+1$. São levados em consideração, além das propriedades dos schemas, a população e os efeitos dos operadores genéticos seleção, crossover e mutação.

A seleção dos melhores cromossomos exploraria regiões aparentemente promissoras do espaço de busca, o crossover agregaria schemas bons e a mutação serviria para manter a variabilidade da população [16].

Um efeito do operador de seleção é aumentar ou diminuir o número de instâncias de determinados schemas na população. Se a seleção garantir que cromossomos com uma aptidão acima da média tenham maiores chances de serem escolhidos, então a quantidade de instâncias de certos schemas irá aumentar. Isso acontece pois os indivíduos gerados na reprodução podem guardar semelhança com seus progenitores. Portanto o número de instâncias de schemas com aptidão acima da média aumentará. Como demonstrado por Goldberg, esse crescimento é exponencial [19].

Apesar da seleção ter a característica de explorar os melhores schemas da população, por si só não garante a sua evolução, já que lhe falta a variabilidade genética. Se a reprodução apenas duplicasse os indivíduos previamente selecionados, nenhuma informação nova seria adicionada à população. Por isso existe o operador de crossover. O conteúdo de 
dois cromossomos são então combinados aleatoriamente, gerando dois novos cromossomos, cada qual contendo partes de ambos os progenitores.

O terceiro operador genético, mutação, também pode acontecer durante a reprodução. Seu efeito é o de alterar pontualmente os schemas existentes. Por vezes essa alteração pode destruir schemas, especialmente os de maior comprimento.

Com essas informações é possível então se enunciar o teorema dos schemas: schemas curtos, de baixa ordem, de aptidão acima da média receberão um número de instâncias cada vez maior (exponencial) nas gerações seguintes [19].

O trabalho de Holland foi inovador em sua época por reunir os operadores genéticos (crossover, mutação e inversão) a um algoritmo de busca baseado em população, além de ser um dos pioneiros na busca de uma teoria matemática sólida que respaldasse o funcionamento dos algoritmos genéticos. Entretanto, nenhum modelo atualmente consegue propor uma descrição completa [12]. Mesmo assim os algoritmos genéticos têm se mostrado eficientes em problemas reais, como projetos de engenharia [20] e uma grande variedade de problemas clássicos, como problemas de otimização não-linear, geração de árvore mínimas, problema do caixeiro viajante e outros [18] [16].

\subsubsection{Paralelismo implícito}

Schemas não são avaliados explicitamente mas sim de forma implícita. A avaliação explícita se dá apenas nos cromossomos. Como um schema representa um conjunto de cromossomos, será a média deste conjunto que ditará suas chances de seleção (ou probabilidade de sobrevivência).

Apesar de se processar, a cada iteração, apenas $n$ cromossomos, o algoritmo genético inspeciona um número na ordem de $n^{3}$ schemas. Isto foi chamado de paralelismo implícito 
por Holland e é uma característica dos algoritmos genéticos [19][16][20].

Um cromossomo pertence a $2^{l}$ schemas diferentes, onde $l$ é o tamanho do schema medido em caracteres. Entretanto, para se chegar ao referido número de schemas processados considera-se, para cada cromossomo, apenas os schemas que possuam uma probabilidade de sobrevivência acima de certo limiar. Com esta primeira restrição, o tamanho dos schemas fica limitado a um determinado comprimento (segunda restrição). Contando os schemas que satisfazem tais critérios e escolhendo convenientemente o valor do tamanho da população, chega-se ao número de $n^{3}$ schemas processados a cada iteração. Para se escolher o tamanho da população convenientemente esta deve conter não mais do que um schema de comprimento igual ao limite (segunda restrição), para cada cromossomo.

Uma forma bastante simplificada de se entender como se chega a tal número é mostrada a seguir. Um cromossomo pode pertencer a até $2^{l}$ schemas. Portanto, a quantidade de schemas de uma população contendo $n$ cromossomos pode chegar a até $n .2^{l}$ schemas. Um tamanho de população que satisfaz a a primeira restrição, mencionada anteriormente, é $2^{1 / 2}$. Portanto $n \cdot 2^{l}=n \cdot 2^{l / 2} \cdot 2^{l / 2}=n^{3}$. 


\section{BIOINFORMÁTICA}

O ano de 2000 entrou para a história como sendo o ano de publicação do primeiro rascunho (draft) do genoma humano, mostrando a vitória do esforço de inúmeras instituições em todo o mundo no desafio de tentar decifrar o nosso material genético.

No rastro deste projeto maior, vários outros organismos tiveram seu genoma seqüenciado [10] com interesses variando entre simplicidade do próprio organismo e potencial econômico.

O volume de dados brutos obtido destes trabalhos é bastante expressivo. Os organismos apresentam uma quantidade de material genético que, uma vez seqüenciado, varia de alguns milhares de pares de bases até bilhões, como no caso humano.

As pesquisas sobre os organismos seqüenciados acontecem em campos interdisciplinares e com o qual colaboram biólogos, físicos, químicos, estatísticos e cientistas da computação, para citar apenas alguns. A este campo interdisciplinar, que tem por objetivo analizar dados biológicos para compreensão, interpretação e predição, é dado o nome de bioinformática $[7]$.

A menor unidade de informação manipulada na bioinformática é uma seqüência de nucleotídeos. Aparelhos chamados de seqüenciadores transformam a informação contida nestas seqüências em cadeias de caracteres de comprimento em torno de 700 letras. Entretanto o genoma, ou seja, o conteúdo completo do material genético de um organismo, é normalmente composto de uma quantidade de nucleotídeos várias ordens de grandeza maior que a capacidade destes seqüenciadores.

O genoma de um organismo é dividido em cromossomos. Cada cromossomo, por sua vez, possui uma quantidade variável de genes.

Genes são basicamente uma seqüência de comprimento variável de nucleotídeos. Duas 
de suas principais funções: síntese de proteínas, as quais regulam e controlam processos vitais de um organismo; produção de moléculas de RNA não codificantes, que é relacionado à regulação gênica.

Desta forma um cromossomo precisa ser decomposto em unidades pequenas o suficiente para poderem ser seqüenciados. Feito isso, os trechos são submetidos a bancos de dados onde são tornados públicos para a comunidade científica.

\subsection{Alinhamentos em bioinformática}

Dentre as possíveis análises que podem ser realizadas sobre os dados seqüenciados, [21] citam: análise de seqüências simples utilizando bases de conhecimento, comparação entre pares de seqüências e buscas baseadas em seqüências, alinhamento múltiplo de seqüências, descoberta de motivos em alinhamentos múltiplos e inferência filogenética. Direta ou indiretamente muitas destas tarefas se valem de alinhamentos, sendo por isso uma das aplicações computacionais mais utilizadas.

Uma possível definição de alinhamento de seqüências foi dada por [9]: dado um alfabeto finito $A$, sejam $s$ e $t$ duas cadeias sobre $A$ de comprimento $m$ e $n$, respectivamente. Seja $A^{*}=$ $A \mathrm{U}\{-\}$ um alfabeto finito onde "-” representa o caracter de espaço (gap). A tupla $\left(s^{*}, t^{*}\right)$ representa um alinhamento de $s$ e $t$ se as seguintes propriedades são satisfeitas:

As cadeias $s^{*}$ e $t^{*}$ possuem o mesmo comprimento, $\left|s^{*}\right|=\left|t^{*}\right|$;

$s^{*}{ }_{i}$ e $t^{*}{ }_{i} \neq "=", 0<=\mathrm{i}<=\left|s^{*}\right|$. Ou seja, não existem dois espaços na mesma posição em $S^{*} \mathrm{e} t^{*}$

Eliminando os buracos, $s^{*}$ é reduzido para $s$;

Eliminando os buracos, $t^{*}$ é reduzido para $t$.

Para as seqüências de DNA, o alfabeto é $A^{*}=\{\mathrm{A}, \mathrm{G}, \mathrm{C}, \mathrm{T},-\}$ (quatro nucleotídeos mais 
o espaço). No caso de um alfabeto de aminoácidos, $A^{*}=\{A, C, D, E, F, G, H, I, K, L, M$, $N, P, Q, R, S, T, V, W, Z,-\}$ (vinte aminoácidos mais o espaço).

O alinhamento de seqüências pode ser analisado como um problema de otimização. Para cada par de elementos da seqüência a ser alinhada escolhe-se o melhor pareamento segundo um esquema de pontuação, de forma a se obter um valor que indique a qualidade do alinhamento. Busca-se, portanto, maximizar tal valor.

O esquema de pontuação citado anteriormente refere-se a um valor atribuído ao pareamento entre dois elementos de um alinhamento, aminoácidos ou nucleotídeos. No caso de alinhamento simples, ocorre apenas um pareamento por posição do alinhamento. Somando-se os valores de cada posição do alinhamento obtém-se sua pontuação total.

Um exemplo de esquema de pontuação seria o caso onde, em uma determinada posição do alinhamento, houvesse o mesmo nucleotídeo em ambas as seqüências analisadas (pareamento correto), que receberia pontuação de valor 1. No caso de um pareamento incorreto (nucleotídeos diferentes) a pontuação receberia valor -1. E no caso de uma das posições conter um espaço (gap), a pontuação -2 .

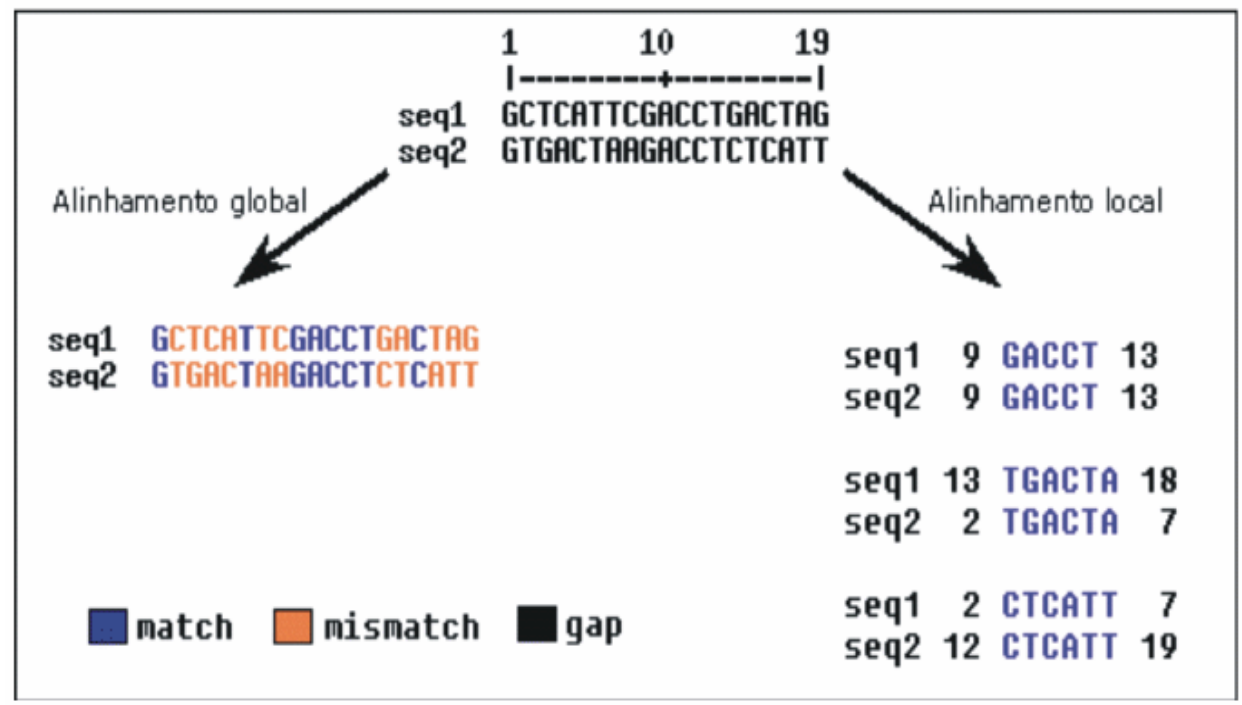

Figura 5: Alinhamento simples: local e global 
Na Figura 5 é exemplificado um trecho de um alinhamento simples. Se fosse utilizado o esquema de pontuação citado anteriormente, a primeira posição do alinhamento (primeira coluna a esquerda) obteria pontuação -2, assim como a última coluna. A segunda e terceira coluna obteriam, cada uma, pontuação 1 (pareamento correto). E a penúltima coluna, um pareamento incorreto, pontuação -1 . O valor total deste alinhamento seria então $-2+1+1$ $-1-2=-3$

Modelos mais complexos de pontuação de seqüências foram desenvolvidos dando origem às matrizes de substituição PAM e BLOSUM. Essas matrizes podem incorporar símbolos ambígüos de DNA e informações de análises mutacionais, que revelam transições e transversões entre nucleotídeos bem como taxa de substituição de aminoácidos [1].

Assim, o alinhamento ótimo será aquele que obtiver melhor pontuação, que é definida pela similaridade entre duas seqüências [9].

\subsection{Multialinhamento de seqüências}

Multialinhamentos são casos generalizados de alinhamento simples, onde várias seqüências são alinhadas simultaneamente da melhor forma possível.

Alinhamentos múltiplos são importantes pois podem revelar sítios no DNA ou em proteínas que podem se mostrar funcionalmente importantes. A homologia dentro de uma determinada família de seqüências também pode ser estudada uma vez que estas tenham sido alinhadas. A filogenia se utiliza desta técnica para iniciar seus estudos sobre a história da evolução de partes do genoma, que podem vir a refletir a evolução dos próprios organismos analisados [1].

Reconhecimento de padrões nos dados analisados pode ser útil em se procurar motivos (motifs) em seqüências de amino-ácidos de uma proteína. Sítios ditos conservados refletem 
uma pressão seletiva da natureza, uma preocupação considerável para que aquele determinado trecho fosse mantido livre de mutações, ao se analisar uma família de dados. Estas informações podem ser importantes em estudos funcionais e estruturais de proteínas.

Observa-se que o multialinhamento possui um papel importante em várias destas técnicas por ser uma das primeiras ferramentas aplicadas aos dados e sobre os quais cada técnica realizará suas atividades específicas.

\subsection{Alinhamento global e alinhamento local}

Há duas formas de se alinhar um par de seqüências: alinhamento global e alinhamento local [1].

O algoritmo para alinhamento global foi criado por Needleman e Wunsch e procura parear (matching) o máximo de posições em toda a extensão das seqüências.

Para o alinhamento hipotético de duas proteínas é construída uma matriz. As seqüências são colocadas sobre cada um dos eixos da matriz. Esta é então preenchida com valores numéricos que variam conforme o aminoácido que se encontra em cada um dos eixos. A solução é obtida ao se percorrer, seguindo certas regras, um determinado caminho. O problema torna-se análogo a um problema de minimização de custo de um caminho dentro de um dígrafo, ou seja, um problema de otimização.

O algoritmo para alinhamento local foi criado por Smith e Waterman e é utilizado no caso de seqüências pouco similares com o propósito de se identificar regiões conservadas, ou seja, trechos que são comuns às seqüências de entrada. A construção da solução acontece de forma semelhante ao algoritmo de Needleman e Wunsch, com exceção ao caminho percorrido dentro da matriz. Essa mudança é decorrente da maior prioridade que se dá ao pareamento de trechos altamente similares em detrimento da extensão do 
alinhamento.

Estes algoritmos executam o alinhamento chamado de exato e seu resultado é o alinhamento ótimo [1].

\subsection{Complexidade do problema}

Ambos os algoritmos são implementados utilizando a técnica de programação dinâmica e, conforme provado por [9] a complexidade, tanto espacial quanto temporal, é da ordem de $\mathrm{O}(m . n)$, onde $m$ é o comprimento da primeira seqüência, e $n$, da segunda. Para amostras de comprimento semelhantes, o algoritmo torna-se então de ordem quadrática. Algumas melhorias, também analisadas por [9], baixam a complexidade do algoritmo até a ordem linear mas impõem certas limitações que restringem seu uso.

No caso de multialinhamentos a solução pode ser vista como análoga ao alinhamento simples, mas utilizando matrizes com um número dimensões igual ao número de seqüências.

Se os algoritmos acima apresentados fossem utilizados para o caso de multialinhamento, a complexidade, conforme [9] para este algoritmo seria da ordem de $\mathrm{O}\left(k^{2} \cdot 2^{k} \cdot n^{k}\right)$, onde $k$ é o número de seqüências e $n$ é o comprimento destas, sendo este um caso de problema NPcompleto.

Algoritmos enumerativos, como a programação dinâmica, se mostram ineficazes quando o número de seqüências analisadas cresce além de um determinado limiar prático. Não havendo uma solução polinomial para este problema, e sendo um caso de otimização, o uso de algoritmo genético mostra-se a princípio adequado para tal problema ([3]; [6])

Os principais desafios encontrados nesta tarefa, segundo [1] seriam: encontrar um alinhamento ótimo para mais de duas seqüências onde ocorrem acertos (matches), erros (mismatches), espaços (gaps) e levando-se em conta, ainda, o grau de variação das próprias 
seqüências. Outro desafio é encontrar uma função que reflita de forma apurada o grau de alinhamento acumulado, durante a execução do alinhamento. Por fim, encontrar uma política adequada para pontuação dos espaços.

\subsection{Algoritmos de multialinhamento}

O algoritmo de alinhamento global de Needleman e Wunsch é um exemplo do chamado algoritmo de alinhamento exato sendo o programa $M S A$, de autoria de Lipman, um exemplo implementação existente. Utilizando programação dinâmica e construindo uma matriz de pontuação é possível alinhar otimamente um par de seqüências. Ao se generalizar tal algoritmo para mais de duas seqüências os recursos computacionais necessários crescem a ponto de impedir sua utilização sobre mais de três seqüências. Com a utilização de heurísticas que limitam o espaço de busca deste algoritmo torna-se possível processar até dez seqüências, mas com a desvantagem de se perder a garantia de que a solução encontrada é a ótima. O que se tem, portanto, são limites para a solução obtida [22].

Como observado em [23], o resultado ótimo obtido nestes alinhamentos provê um bom alinhamento, mas não melhor do que de outras técnicas, como o alinhamento progressivo. A função matemática utilizada no alinhamento não necessariamente possui significado biológico.

O alinhamento progressivo é um dos métodos mais simples e mesmo não havendo garantias de qualquer nível de otimização [7] ainda assim tornou-se o método padrão para multialinhamento por meio do programa ClustalW.

O objetivo do ClustalW é otimizar a pontuação de um alinhamento. Cada pontuação possui um valor agregado que pondera sua contribuição no resultado final bem como penalidades aplicadas aos espaços (gaps). Um pré-processamento é realizado sobre as 
seqüências gerando uma árvore (dendograma). Esta árvore guia o processo de alinhamento ao mostrar a ordem em que as seqüências devem ser adicionadas ao alinhamento múltiplo, num processo progressivo. Uma vez que um trecho foi alinhado, este não é desfeito, mesmo que informações posteriores conflitem com este alinhamento inicial.

O principal problema deste tipo de algoritmo é a dependência do primeiro alinhamento [1]. O primeiro par alinhado deve ser o mais similar possível. Um alinhamento inicial com poucos erros gerará um resultado com poucos erros. Por outro lado, se o par inicial for pouco similar, os erros de alinhamento serão propagados durante todo o processo.

Segundo [22], os algoritmo iterativos iniciam com um alinhamento que é iterativamente melhorado por meio de pequenas modificações. O algoritmo é encerrado quando nenhuma modificação pode melhorar o resultado obtido. O modo como estas modificações são realizadas pode ser determinístico ou estocástico. O método determinístico pode utilizar a programação dinâmica, enquanto o método estocástico é implementado por simulated annealing (SA) ou algoritmos genéticos (AG).

O algoritmo iterativo estocástico segue um procedimento comum onde alterações aleatórias no alinhamento são geradas. Estas modificações podem ser mantidas ou descartadas, de acordo com os efeitos da mudança sobre o alinhamento.

O uso de algoritmos genéticos na análise de seqüências foi primeiro apresentado por Ishikawa em 1993 [24], em um algoritmo híbrido que otimizava a ordem em que as seqüências eram apresentadas a um algoritmo de programação dinâmica, ou seja, o algoritmo genético não realizava alinhamento, mas apenas otimizava o conjunto de dados para outra técnica. Apesar desta abordagem limitar o uso do programa às restrições da programação dinâmica, os resultados encontrados foram encorajadores, como mostrado em 
1995 por Isokawa em seu programa MAGA (Multiple Alignment by Genetic Algorithm) [3]. Notredame e Higgins apresentaram no ano seguinte o programa SAGA (Sequence Alignment by Genetic Algorithm) [6]. Tanto no $M A G A$ quanto no $S A G A$ cada indivíduo da população era representado por um alinhamento completo. Estes indivíduos competem entre si pela sobrevivência, nos moldes do algoritmo genético simples ( $s g a$ ) de Goldberg. O $S A G A$, em especial, contém um conjunto de 20 operadores de mutação que, de forma estocástica, produzem alterações nos alinhamentos. Não há garantias no resultado encontrado, mas [22] cita resultados onde o $S A G A$ possui desempenho melhor ou superior ao MSA. Resultados semelhantes são apresentados em ([4]; [2]; [5]) onde o $M A G A$ e o ClustalW são comparados.

Mais recentemente informações como análise estrutural, comparativos entre seqüências, busca em bancos de dados e conhecimento empírico foram utilizadas na geração de uma nova tabela de valores de pareamentos. Esta biblioteca, bem como uma nova função objetivo que fizesse uso destas informações, foram utilizados pelo $S A G A$ para encontrar o alinhamento com maior nível de consistência com estas informações. Este conjunto recebeu o nome de SAGA-COFFEE. Uma variante (T-COFFEE) foi construída para melhorar a performance deste programa, agora utilizando uma implementação progressiva, similar ao ClustalW. Resultados [22] mostram que a performance do T-COFFEE chegam a ser superiores ao do ClustalW e outros programas.

\subsection{SGA para multialinhamento}

Esta Seção descreve como adaptar um sga proposto por Goldberg para multialinhamento de seqüências. A codificação do cromossomo será baseado no trabalho de Isokawa [3]. Cada cromossomo representará um alinhamento completo das seqüências de entrada. A 
representação será feita, inicialmente, por uma matriz de bits de dimensões $m$ e $n$, onde $m$ é o comprimento da maior seqüência e $n$ é a quantidade de seqüências a serem alinhadas.

Nesta matriz cada posição será preenchida com os valores "0" ou "1". O primeiro representa ausência (gap) de um elemento da seqüência, enquanto o último indica sua presença. Seja o alinhamento entre três seqüências hipotéticas de nucleotídeos:

$$
\begin{aligned}
& \mathrm{S} 1=\mathrm{G} \mathrm{A} \mathrm{T} \mathrm{A} \mathrm{C} \mathrm{A} \\
& \mathrm{S} 2=\text { C A T A A } \\
& \mathrm{S} 3=\text { A A T }
\end{aligned}
$$

Completando com espaços no final das seqüências, de forma que todas passem a ter o mesmo comprimento, a representação deste alinhamento no cromossomo (matriz de dimensões 6x3) seria:

\section{1}

111110

\section{0}

A população será um conjunto destes cromossomos. No início do algoritmo, a população inicial é criada aleatoriamente. Isso é feito permutando os elementos de cada linha da matriz entre si. Uma possível permutação para a terceira linha da matriz exemplo seria: “101010”.

A avaliação dos indivíduos é feita através do uso de uma matriz de substituição ( $P A M$ por exemplo). Para cada coluna do alinhamento, todos os pares de nucleotídeos serão convertidos em valores. Estes serão acumulados de uma coluna para outra e dará o valor final do alinhamento. No exemplo, na primeira coluna seriam feitas três comparações de nucleotídeos usando a matriz de substituição: $(G, C),(G, A),(C, A)$. Supondo que o valor 
para estes pares sejam respectivamente V1, V2 e V3, o valor do alinhamento, após computada a primeira coluna, seria $\mathrm{V}=\mathrm{V} 1+\mathrm{V} 2+\mathrm{V} 3$. Este processo se repete para as demais colunas, sempre acumulando os valores.

Na matriz de substituição não há valores para os espaços (gaps). É necessário definir um valor a ser utilizado caso se encontrem espaços no alinhamento. Uma política simples para pontuação neste caso seria atribuir toda comparação envolvendo espaços um único valor. Outras políticas mais elaboradas atribuem valores diferenciados para espaços conforme estes estejam iniciando uma seqüência de espaços ou não. Normalmente estes valores são todos negativos, ou sejam, são penalidades para o cromossomo. Encontrar posições que minimizem o efeito destas penalidades é o objetivo do algoritmo genético.

Uma vez que todos os cromossomos foram avaliados e um valor foi atribuído a cada um destes (valor de aptidão), deve-se selecionar alguns indivíduos para geração da prole. A seleção dos pais é feita pelo método de torneio [18]: dentre um conjunto de $x$ cromossomos sorteados aleatoriamente, aquele com maior aptidão é selecionado. A geração da prole é feita por clonagem, recombinação (crossover) e mutação. A clonagem gera apenas cópias de um indivíduo enquanto o crossover faz a recombinação de dois indivíduos e a mutação insere uma mudança no conteúdo de um cromossomo. Inicialmente a recombinação será baseado em [6] e a mutação, em [3]. Estas escolhas foram feitas pela simplicidade de implementação e uma mudança nestes operadores poderá ocorrer quando um aumento de performance for desejável.

A prole recém gerada substituirá parte da população de várias formas possíveis, e o efeito de cada uma será analisado e o mais interessante será então escolhido. A substituição pode se dar de forma determinística (substituir determinados elementos, como por exemplo, 
os piores) ou estocástica (torneio, seleção aleatória etc).

Uma pequena parcela da população (os de maior aptidão) será obrigatoriamente preservada, implementando assim o elitismo, visando um aumento da performance [19].

A qualidade dos alinhamentos obtidos pelo sga para multialinhamento é muito inferior quando comparados aos produzido pelo algoritmo genético SAGA, algoritmo genético com melhor desempenho para multialinhamento encontrado na literatura. O desempenho relativamente baixo do sga para multialinhamento deve-se ao fato do deste problema possuir características muito específicas, requerendo operadores mais elaborados que do sga para se conseguir explorar adequadamente o espaço de busca. O Capítulo 4 apresenta o SAGA e os resultados obtidos com este algoritmo. 


\section{ALGORITMO SAGA}

O SAGA pode ser considerado a principal abordagem estocástica para multialinhamento devido aos resultados relatados em [6][22]. A Seção 4.1 descreve o SAGA, destacando sua estrutura de dados e seus operadores genéticos, que são seu principal diferencial. Os resultados obtidos com a implementação do SAGA e encontrados na literatura são discutidos na Seção 4.2.

\subsection{SAGA}

SAGA (sequence alignment by genetic algorithm) é composto por um conjunto de 22 operadores que são utilizados para evoluir uma população de alinhamentos. A cada iteração avalia-se a qualidade de seus indivíduos segundo uma função objetivo. Uma parte da população é então selecionada e sofre ação dos operadores que agem sobre um ou mais indivíduos. Procura-se com isso melhorar a aptidão média da população na esperança de se obter multialinhamentos melhores que os iniciais. Os resultados são comparados com um conjunto de referências composto por seqüências de estrutura terciária conhecidas.

Um grande número de programas de multialinhamento utiliza a abordagem progressiva. Seguindo um certo critério, estabelece-se uma ordem. As duas primeiras seqüências são alinhadas entre si. A este resultado é adicionada a terceira seqüência e assim por diante até que todas sejam agregadas. Não há uma função objetivo a se seguir, mas apenas uma ordem de adição das seqüências. Uma das principais desvantagens está incapacidade de se alterar o alinhamento obtido. Após duas seqüências serem alinhadas, estas permanecem inalteradas, sendo que apenas as novas seqüências agregadas é que podem ser arranjadas durante as iterações seguintes. Dessa forma, quaisquer erros cometidos em etapas intermediárias serão agregadas ao resultado final. 
Duas abordagens alternativas ao multialinhamento progressivo são HMM e OF. Cadeias ocultas de Markov (Hidden Markov Models) buscam um modelo probabilístico para os eventos de substituição, inserção e deleção de pares de base do alinhamento. Outra abordagem utiliza funções objetivo (objective function) na avaliação dos indivíduos da população. Esta função permite comparar entre dois alinhamentos e decidir por um, cuja qualidade, espera-se, seja maior. O resultado final depende então da função objetivo escolhida.

SAGA utiliza algoritmos genéticos para otimizar a função objetivo (soma de pares) durante o alinhamento progressivo. Seus resultados são comparáveis aos de outros programas (MSA e ClustalW) comumente utilizados para esta tarefa.

A soma de pares é o nome genérico de uma técnica que utiliza uma função objetivo para mensurar a qualidade de um multialinhamento. Um custo é associado a cada par de base pareado (custo de substituição), bem como para os buracos (custo de gap). A soma destes custos em toda a extensão do alinhamento reflete a qualidade do alinhamento. Três fatores podem ser alterados: conjunto de pesos para o custo de substituição; custo de substituição (tabelas PAM e BLOSUM, por exemplo); forma de contagem dos custos.

O algoritmo genético utilizado pelo SAGA é baseado no simple genetic algorithm de Goldberg. Soluções aleatórias para o problema são codificadas e inseridas em um conjunto chamado de população. Essa população possui um número de indivíduos constante durante toda a execução do programa e passa por iterações (gerações) onde uma parte de seus elementos é substituída por indivíduos criados de duas formas: ou por alteração de um outro indivíduo existente (mutação), ou pela combinação de dois outros indivíduos existentes (recombinação). A escolha de quais indivíduos sofrerão estas operações é feita 
segundo um critério (operador de seleção) que compara as aptidões entre indivíduos. Com o sucessão de iterações pode ocorrer uma melhoria na aptidão média da população uma vez que novas formas de arranjo das seqüências são geradas (mutação) e estas são agregadas (recombinação) de forma que os melhores resultados são escolhidos em detrimento dos demais. Quando não há mais melhorias dentre um certo número de iterações, escolhe-se o melhor indivíduo e a solução que este carrega é a solução apresentada pelo algoritmo genético para o problema.

Os operadores do SAGA podem ser divididos em dois tipos: os que utilizam apenas um único indivíduo, chamados de mutação, e os que utilizam dois indivíduos, chamados de recombinação ou crossover. O primeiro gera novos arranjos enquanto o segundo combina trechos na esperança de que dois indivíduos bons gerem um terceiro ainda melhor.

Uma particularidade do SAGA é a utilização de uma busca exaustiva pelo melhor valor dos parâmetro envolvidos na utilização de seus operadores. Os operadores apresentam-se em duas formas: parâmetros aleatórios ou não. No caso não aleatório, a variável em questão será inspecionada dentro de um intervalo arbitrário de valores e o melhor resultado é utilizado.

Duas formas de recombinação são implementadas no SAGA: um-ponto e uniforme. Na recombinação de um ponto, escolhe-se aleatoriamente uma coluna no multialinhamento, dividindo-o em duas partes. Realiza-se então uma troca dessas partes entre os indivíduos. Na recombinação uniforme, quebra-se a seqüência não mais em duas partes, mas em várias partes. Os pontos de quebra são escolhidos segundo um certo critério e os trechos entre estes pontos são intercambiados entre os indivíduos envolvidos.

Inserção de buracos (gap insertion) é o operador de mutação mais simples. Divide-se as 
seqüências em dois conjuntos, baseado na similaridade estimada por uma árvore filogenética. Em cada um destes conjuntos faz-se uma inserção de uma mesma quantidade arbitrária de espaços contígüos.

O operador block-shuffling realiza deslocamentos de blocos de caracteres. Estes blocos podem tanto ser resíduos ou espaços, mas não ambos simultaneamente. Definido um bloco, este pode ser deslocado para esquerda ou direita. O bloco pode ainda ser dividido tanto verticalmente (quebra em uma determinada coluna), realizando inserções em seu meio de forma a separar ambas as partes, quanto horizontalmente. Neste último caso, leva-se em consideração a árvore-guia, que fornece 2 partições para as seqüências. Cada partição é então deslocada para uma das direções.

O operador block-searching procura uma determinada cadeia de caracteres dentro de um certo limite. Se esta cadeia for encontrada em todas as seqüências dentro dos limites especificados para busca, tenta-se inserir e remover espaços das seqüências de forma que esta cadeia fique pareada da melhor forma possível. Qual a cadeia escolhida, seu comprimento, e o espaço de busca são todos parâmetros arbitrários, sendo que os valores típicos são de 5 a 15 caracteres para a cadeia e o espaço de busca ocorre entre 50 a 150 caracteres ao redor da cadeia sorteada. Este operador é o que causa as maiores mudanças dentro de um indivíduo.

\subsection{Análise de resultados}

Baseado no artigo do SAGA, implementou-se um algoritmo genético para multialinhamento de seqüências. Baseando-se na rapidez da implementação, escolheu-se 19 dos 22 operadores. Os operadores não implementados utilizam um outro algoritmo genético para fazer otimização de alinhamento dentro de um trecho arbitrário, chamado de 
micro-algoritmo genético, já que a quantidade de indivíduos na população e o número de iterações são reduzidos. Seria algo que tomaria um tempo para implementar e, principalmente, ter seus parâmetros ajustados (já que no artigo original não há quaisquer informações acerca dos parâmetros utilizados).

Segue abaixo a listagem dos operadores implementados:

1. Stochastic Whole block Left

2. Stochastic Whole block Right

3. Deterministic Whole block Left

4. Deterministic Whole block Right

5. Stochastic Vertical block Left

6. Stochastic Vertical block Right

7. Deterministic Vertical block Left

8. Deterministic Vertical block Right

9. Stochastic Horizontal block Left

10. Stochastic Horizontal block Right

11. Deterministic Horizontal block Left

12. Deterministic Horizontal block Right

13. Deterministic Crossover 1 point

14. Stochastic Crossover 1 point

15. Deterministic Crossover uniform

16. Stochastic Crossover uniform

17. Stochastic Gap insertion

18. Stochastic Gap insertion 
19. Block searching

O conjunto de testes utilizado foi obtido do BAliBASE [40]. Esta é uma base de dados internacional com informações disponibilizadas por acesso a internet. Os conjuntos de seqüências do BAliBASE foram gerados por biólogos pesquisadores em filogenia para se conseguir uma base criteriosa para avaliação de desempenho de estratégias de construção de filogenias. Esses conjuntos de seqüências estão divididos em 8 grupos.

Para os testes apresentados a seguir, foram escolhidas 3 amostras de cada um desses grupos, totalizando 24 casos de teste. Para cada um dos 8 grupos, os elementos foram ordenados de acordo com a quantidade de pares de base da amostra. Estas foram então divididas em 3 subgrupos com aproximadamente a mesma quantidade de elementos e de cada um destes subgrupos sorteou-se um elemento. Cada um dos 24 casos de teste possui várias seqüências (em torno de uma dezena) de até mil pares de base de extensão.

Para comparação, implementou-se um algoritmo de programação dinâmica baseado no artigo do ClustalW. Esse algoritmo realiza um alinhamento progressivo mas utilizando um método determinístico para realizar os alinhamentos. Escolheu-se comparar o AG com uma implementação simples do ClustalW para que apenas a essência das técnicas (e não as heurísticas $a d-h o c$ ) fossem levadas em consideração.

Para mensurar os resultados utilizou-se o programa baliscore, que faz parte do conjunto BAliBASE. Este programa compara o alinhamento em questão com o alinhamento feito por especialistas. O resultado desta comparação é apresentado na Figura 6.

O desempenho do AG varia entre $40 \%$ a $90 \%$ do resultado obtido pela implementação do ClustalW. Nas primeiras amostras, que contém poucas seqüências curtas, é onde o AG apresenta melhores resultados, variando entre $80 \%$ a $90 \%$. Nas amostras situadas no meio 
do eixo $\mathrm{X}$, com seqüências de comprimento intermediário, a variação do desempenho é maior, ficando entre $60 \%$ e $80 \%$. No último terço do gráfico, onde estão as seqüências longas, é que se observa a maior variação, ficando entre $40 \%$ e $70 \%$.

\section{Desempenho do AG}

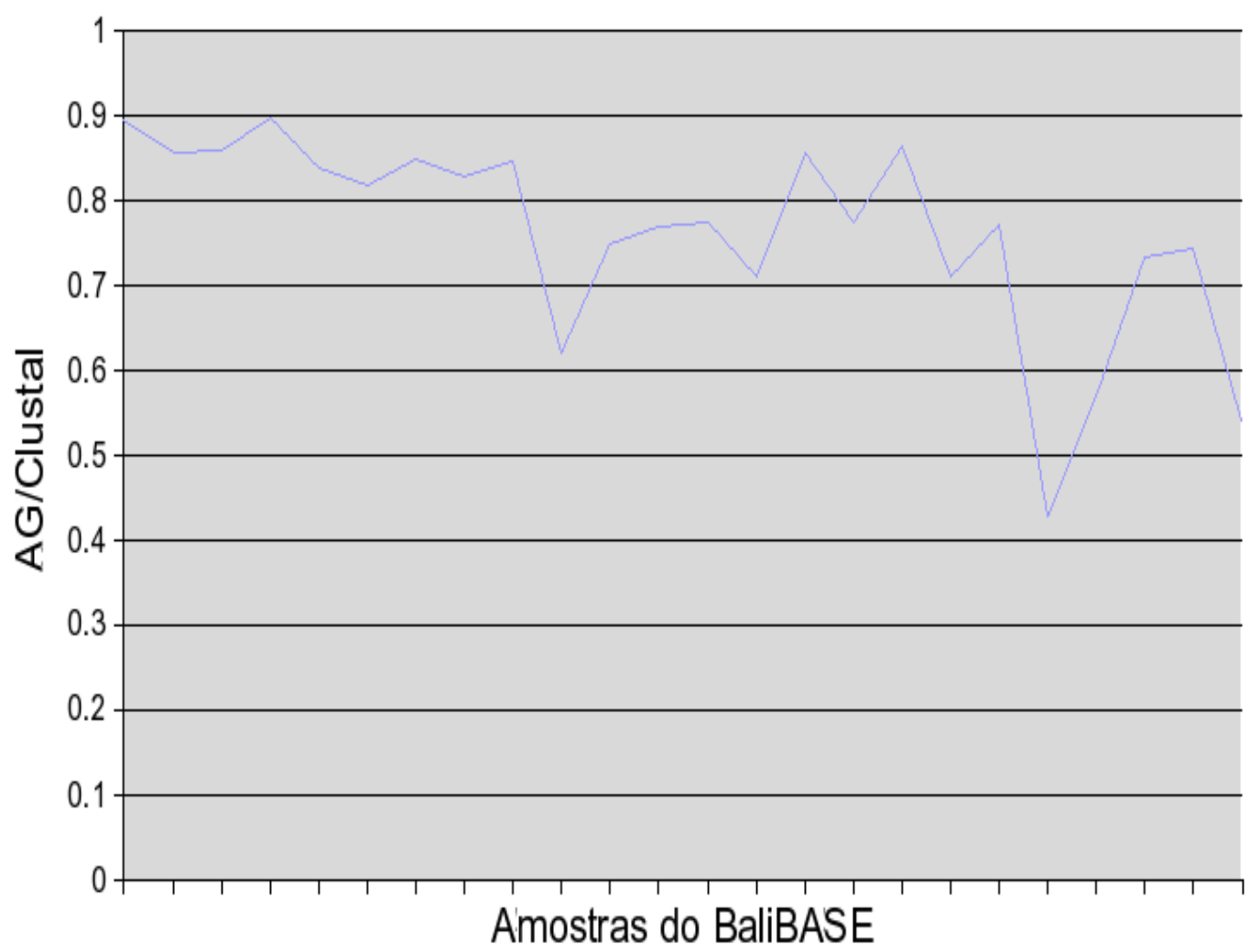

Figura 6: Desempenho da implementação do SAGA comparado com ClustalW.

Diante dos resultados insatisfatórios obtidos com o SAGA, a técnica de algoritmos evolutivos baseada no conceito de self organized criticality foi investigada. Trabalhos da literatura aponto que mudança esporádicas no ambiente, como terremotos, que provocam a eliminação de grande quantidade de indivíduos de uma população, podem cooperar significativamente no processo evolutivo. Os resultados desta área de pesquisa são controversos. A aplicação desta técnica buscando melhorar o SAGA também não 
produziram mudanças de desempenho relevantes. Por outro lado, parte significativa desta pesquisa foi dedicado ao estudo de self organized criticality em vista das potenciais contribuições desta teoria para algoritmos evolutivos aplicados a problemas complexos. A partir deste estudo, conclusões interessantes sobre a área além de perspectivas de novas investigações neste campo foram obtidas. Esses resultados são apresentados no Apêndice, uma vez que não abordam o propósito principal deste projeto apesar de sua relevância. 


\section{BUSCA POR FILOGENIAS PARA}

\section{MULTIALINHAMENTO}

A estratégia de multialinhamento progressivo é, na prática, o procedimento que tem apresentado melhores resultados práticos, sendo o algoritmo Clustal um dos seus principais representantes. Por outro lado, o desempenho desta técnica é extremamente afetado pela ordem em que os pares são alinhados. Há algumas estratégias básicas para se escolher a ordem dos alinhamentos. Setubal e Meidanis [9] sintetizam-nas como segue:

1) Alinhamentos Estrela

Cada pare de alinhamento é formado utilizando uma seqüência fixa e outra seqüência do conjunto de entrada. A seqüência fixa pode ser vista como o centro de uma estrela (árvore com todos os nós conectados a raiz) e as demais seqüências as pontas da estrela. Neste caso, cada alinhamento é ótimo e rapidamente pode-se obter o alinhamento múltiplo. A qualidade do alinhamento múltiplo é afeta pela escolha da seqüência do centro da estrela. Uma forma é tentar todas as seqüências como centro e selecionar o melhor resultado. Outra forma é computar todos os alinhamentos de pares possíveis e selecionar como estrela a seqüência $s_{c}$ que tem a menor soma de scores dos pares com $s_{c}$;

2) Alinhamentos Árvores

Quanto existe uma árvore filogenética para o conjunto de seqüências a serem alinhadas, esta pode ser utilizada para guiar a ordem em que os pares devem ser alinhados. Em uma filogenia, cada folha da árvore corresponde a uma seqüência. A cada nó interno da árvore pode ser associado uma seqüência. Para cada aresta podese calcular um peso, que é a similaridade das duas seqüências em que a aresta incide. 
Dada uma associação de seqüências aos nós interiores da árvore, pode-se calcular a soma de todos os pesos, que dá o score da árvore. Encontrar a associação de seqüências que minimize este score é o problema de Alinhamento Árvore. Este problema é NP-difícil.

Ao invés de resolver este problema, pode-se utilizar somente a topologia da árvore filogenética para decidir a ordem em que os pares devem ser alinhados. Uma filogenia adequada pode ser também obtida com base em informações biológicas utilizando a experiência e conhecimento de biólogos. Porém, em geral, este conhecimento não está disponível para qualquer conjunto de seqüências, além da dependência de uma filogenia construída manualmente para grandes conjuntos de seqüências ser um processo relativamente muito lento. Assim, ferramentas computacionais utilizam filogenias obtidas por algoritmos. O ClustalW emprega o neighbor-joining [1][23] para obter as filogenias. O neighbor-joining é um algoritmo guloso, isto é, restringe o espaço de busca as melhores possibilidades observadas localmente no processo de construção da árvore. Algoritmos gulosos são caracterizados por obterem de soluções satisfatórias com relativamente pouco tempo de computação. Porém, grande parte do espaço de busca não é investigado por esta estratégia. Para problemas com alta não-linearidade, essa estratégias que exploram melhor o espaço de busca em geral encontram soluções significativamente melhores.

Neste sentido, investigou-se neste trabalho a obtenção de topologias de árvores filogenéticas mais adequadas. A Seção 5.1 apresenta um algoritmo de busca exaustiva e os resultados do multialinhamento com base nas árvores encontradas com esta abordagem. Devido aos resultados motivadores com esta abordagem, buscou-se investigar estratégias mais eficientes para obter filogenias mais adequadas para guiar o multialinhamento. A Seção 
5.2 propõe uma nova abordagem baseada na adaptação de Algoritmos Evolutivos para Projeto de Redes para o problema de filogenia e mostra com realizar esta modelagem.

\subsection{Filogenias por algoritmo de busca exaustiva}

O objetivo deste algoritmo é enumerar todas as configurações possíveis de árvores filogenéticas. Esse problema foi dividido em duas partes: gerar todas as estruturas possíveis de árvores com uma quantidade conhecida de nós; para cada estrutura, gerar todas as permutações entre suas folhas. O resultado é a obtenção de todas as árvores possíveis para uma determinada quantidade de folhas.

Cada uma dessas árvores obtidas foi utilizada como árvore-guia para o programa DP (dynamic programming, implementação simplificada do ClustalW). Para comparação utilizou-se o programa Phylip para gerar outras árvores filogenéticas. A técnica utilizada para tal foi neighbor-joining com parâmetros default.

A geração de todas as topologias de árvores para um conjunto de seqüências requer uma estratégia cuidadosa para se garantir que todas as topologias sejam geradas e que tais topologias sejam efetivamente diferentes. A principal dificuldade para produção dessas topologias é a existência de um número relativamente muito grande de árvores isomorfas. Por exemplo, a troca de qualquer nó interno da árvore não muda a topologia da mesma. A seguir é descrito a estratégia empregada para implementação da busca exaustiva.

\subsection{Funcionamento do algoritmo}

\subsubsection{Representação}

Para representar uma árvore utilizou-se um vetor de vetores de comprimento variável. Seja uma árvore com 6 nós folhas (representadas por letras): 


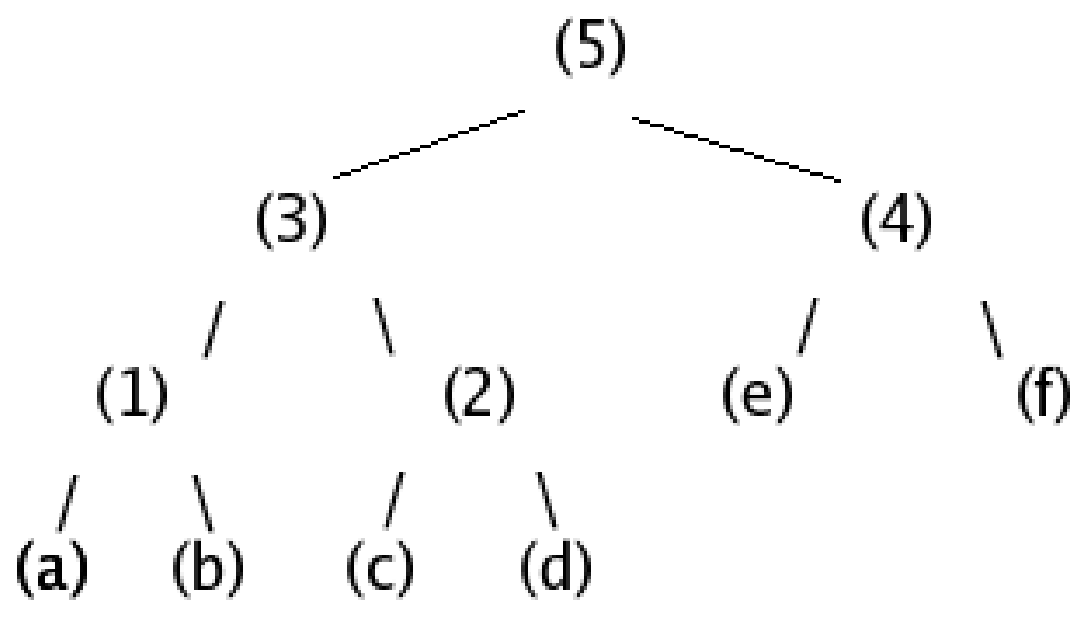

Figura 7: Árvore com 6 nós folhas.

A árvore possui 4 níveis, sendo que o mais inferior contém as folhas $a, b, c$, e $d$. A representação utilizada nesse algoritmo consiste na varredura, linha a linha, de baixo para cima, de uma árvore. No caso do exemplo acima, e escrevendo-se os vetores um ao lado do outro, tem-se:

$$
\text { [a,b,c,d] [1,2,e,f] [3,4] [5] }
$$

Cada nível é representado por um vetor de símbolos. No caso de árvores filogenéticas, e sendo a intenção obter topologias diferentes, os nós internos não são importantes e podem ser representados por um único símbolo. Substituindo os números por -1, e mantendo-se as letras, tem-se:

$$
[\mathrm{a}, \mathrm{b}, \mathrm{c}, \mathrm{d}][-1,-1, \mathrm{e}, \mathrm{f}][-1,-1][-1]
$$

$\mathrm{O}$ vetor da esquerda representa a linha inferior da árvore. Quanto mais para direita está o vetor, mais próximo da raiz estão os nós que este representa.

Um outro exemplo. A árvore com mais níveis é alcançada quando em cada nível (à exceção do mais inferior) possui apenas uma folha. 
(5)

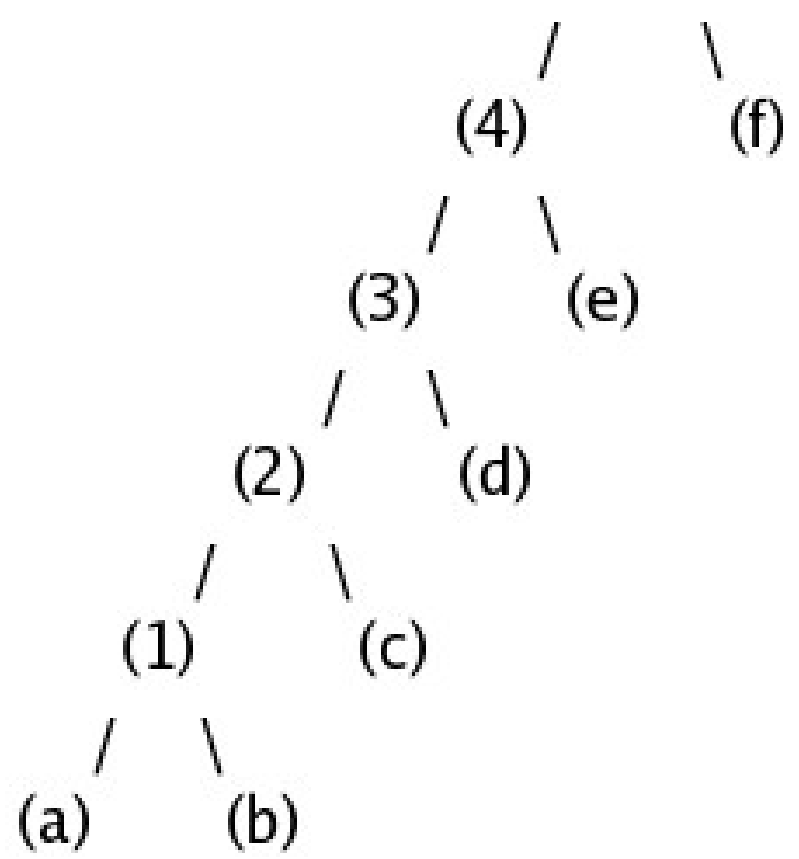

Figura 8: Árvore de 6 nós com altura máxima.

Sua representação seria: $[\mathrm{a}, \mathrm{b}][-1, \mathrm{c}][-1, \mathrm{~d}][-1, \mathrm{e}][-1, \mathrm{f}][-1]$. O nível inferior (primeiro vetor, na representação) é o único com duas folhas. Os demais possuem sempre um par nóinterno/nó-folha.

\subsubsection{Geração das diferentes topologias}

Para gerar todas as topologias possíveis, não se preocupando com o rótulo das folhas que será abordado mais adiante, é preciso enumerar todas as configurações possíveis desses vetores.

Inicia-se colocando no vetor mais a esquerda o maior número possível de nós folhas. Esse número precisa ser expresso sob a forma de potência de 2. Seja essa a condição $C 1$. Assim, no caso de 6 folhas, este número seria 4.

Em seguida preenche-se o próximo nível com nós internos. Cada par de nós no nível $\mathrm{N} 1$ 
adiciona um nó interno no nível $N 2$. Cada novo nível deve também obedecer à condição $C 1$. Essa etapa é repetida até que no nível atual só exista um único nó interno.

Se houver folhas restantes, completar o nível atual obedecendo $C 1$. Se não houver então o processo encerrou sua iteração sendo este último nó interno o nó raiz da árvore.

O vetor de vetores resultante é a topologia resultado, cuja árvore pode ser obtida executando-se o processo inverso da codificação.

Para continuar a gerar as demais topologias, o nível inicial é dividido em dois e inicia-se uma chamada recursiva. O primeiro vetor (nível N1) é fixado, não admitindo alterações. Com isso, no exemplo, o primeiro vetor, que inicialmente continha 4 folhas, passa a conter apenas os 2 primeiros elementos. Completa-se o nível seguinte com nós internos até que para cada par de folhas de N1 haja um nó interno. Em seguida completa-se esse nível com o maior número possível de folhas, obedecendo $C 1$. E assim sucessivamente.

Para 5 folhas, as três topologias admitidas são:

$$
\begin{aligned}
& \mathrm{R} 1:[\mathrm{a}, \mathrm{b}, \mathrm{c}, \mathrm{d}][-1,-1][-1, \mathrm{e}][-1] \\
& \mathrm{R} 2:[\mathrm{a}, \mathrm{b}][-1, \mathrm{c}, \mathrm{d}, \mathrm{e}][-1,-1][-1] \\
& \mathrm{R} 3:[\mathrm{a}, \mathrm{b}][-1, \mathrm{c}][-1, \mathrm{~d}][-1, \mathrm{e}][-1]
\end{aligned}
$$

Observa-se que em $R l$ o nível inicial é o $N 1$ e possui [a,b,c,d].

Em $R 2, N 1$ possui metade de $N 1$ de $R 1$. N2 é preenchido com folhas e o algoritmo prossegue.

Em $R 3$, seu $N 2$ contém a metade de $N 2$ de $R 2$. N3 é preenchido com folhas e nós internos até completar a árvore.

Assim, para uma dada quantidade de folhas pode-se gerar todas as topologias adeqüadas para o uso deste trabalho. 
Para obter-se todas as árvores basta enumerar todas as permutações entre os nós folhas para cada topologia.

\subsubsection{Resultados}

Para avaliar a contribuição de outras topologias de árvores, utilizou-se o algoritmo ClustalW implementado no pacote Phylip [41], substituindo a árvore guia, obtida pelo algoritmo de neighbor-joining pela melhor árvore encontrada de acordo com o algoritmo de busca exaustiva. O critério para avaliação das árvores foi o de parcimônia $[23][25]$.

O dados de seqüências para multialinhamento foram obtidos do BAliBASE. É importante ressaltar que o BAliBASE, além de conjuntos de seqüências adequadas para se avaliar algoritmos para alinhamento, fornece o alinhamento ideal para cada conjunto. Esses alinhamentos foram gerados utilizando o melhor alinhamento encontrado por algoritmo e seguido de posteriores refinamentos nos alinhamentos realizados por pesquisadores da área com base em conhecimento biológicos específicos de cada conjunto de seqüência bem como a experiências dos pesquisadores na área. Com isso, o BAliBASE fornece multialinhamentos com qualidade de alinhamento que são atingíveis por nenhum software disponível hoje. Por outro lado, utiliza-se o grau com que os resultados de um programa aproxima-se dos resultados disponíveis no BAliBASE para se avaliar o desempenho de algoritmos de multialinhamento.

O desempenho da abordagem por topologias obtidas por busca exaustiva não é avaliado com base nos valores ideais do BAliBASE por uma questão conceitual. A abordagem proposta busca evidenciar dois aspectos

1) A existência de topologias de árvores mais adequadas para se guiar multialinhamento 
em estratégias progressivas;

2) A avaliar do grau de contribuição da topologia mais adequada em relação a uma topologia obtida por uma heurística de construção de árvores.

Por outro lado, os algoritmos de multialinhamento utilizam cada vez mais heurísticas baseadas em informações biológicas para guiar o processo de multialinhamento. $\mathrm{O}$ ClustalW, por exemplo, apresenta em sua última versão desempenho muito superior em relação as primeiras versões devido ao acúmulo desse tipo de conhecimento inserido no software. Em resumo, o conjunto dessas heurísticas contribuem fortemente para a melhoria dos alinhamentos. Assim, empregar um algoritmo que utiliza todo o conjunto de heurísticas, para avaliar a influência de uma única heurística (árvores filogenéticas guia) pode dificultar a análise. Além disso, o conjunto de informações biológicas utilizado nos softwares não estão em geral documentados na literatura de forma que se possa incluí-los ou extraí-los de uma algoritmo de multialinhamento para se avaliar a influência de cada heurística ou subconjunto dessas. 


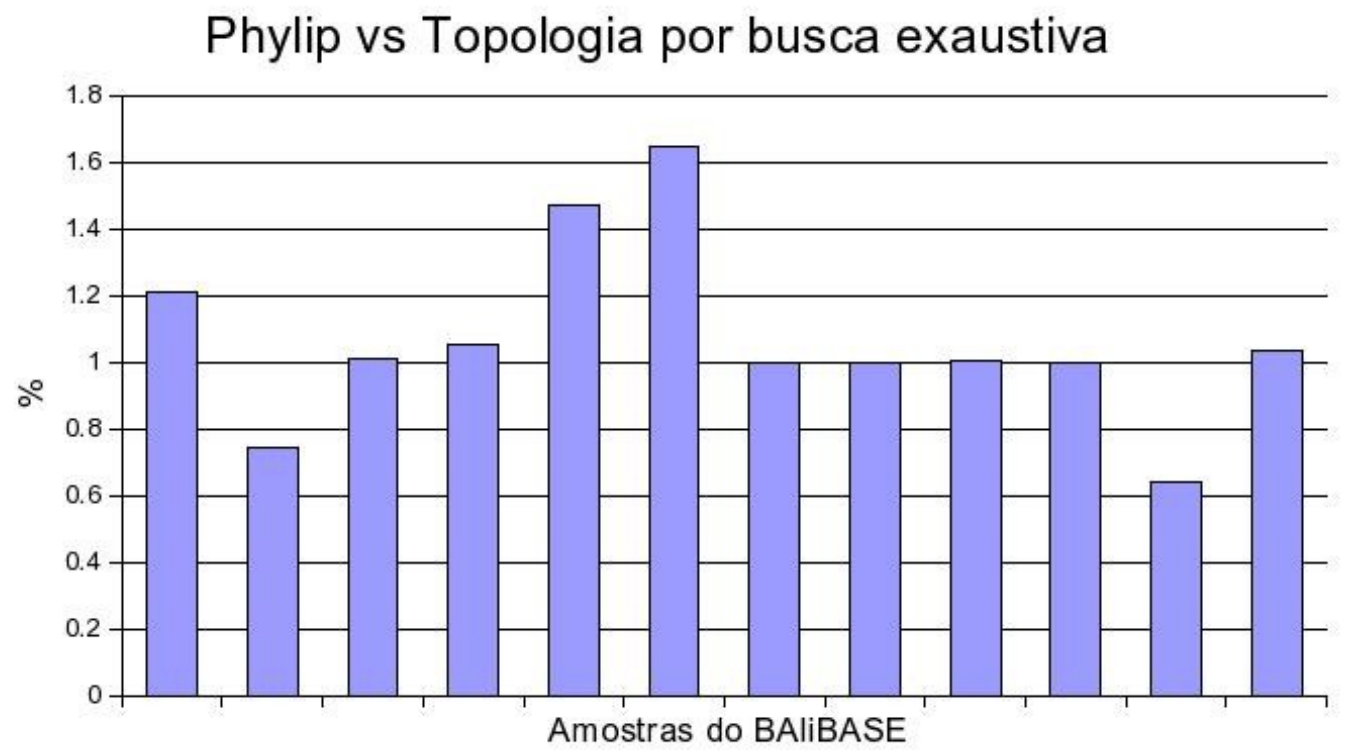

Figura 9: Desempenho da proposta de algoritmo progressivo com melhor árvore guia em relação ao Phylip (ClustalW).

Nesse sentido, optou-se por utilizar o algoritmo ClustalW (do pacote Phylip) em sua primeira versão, que emprega somente a heurística de árvores guia obtida pelo neighborjoining. Os resultados obtidos utilizando a melhor árvore guia produzida pela busca exaustiva são apresentados na Figura 7, que mostra a melhora relativa em porcentagem do multialinhamento para diversos conjuntos de seqüências do BAliBASE. O comportamento ilustrado na Figura 7 é repetido para os demais conjuntos do BAliBASE, ou seja, a estratégia proposta sempre produz um multialinhamento superior ao algoritmo do Phylip.

5.3 Filogenias por abordagem evolutiva de projeto de redes

\subsubsection{Algoritmos de projeto de redes}

Projetos de redes envolvem uma ampla classe de problemas. A solução de um problema de projeto de redes consiste na construção de um grafo que satisfaça certas restrições relacionadas a conectividade e pesos do grafo. Esses tipos de problemas aparecem com 
freqüência em projeto de redes de telecomunicações, restabelecimento de redes de computadores, problemas de transporte, projeto e reconfiguração de circuitos elétricos e eletrônicos. Em [26] são catalogados diversos problemas de projeto de redes, bem como classificados quanto a complexidade computacional [27][28][29][30][31]. A construção de árvores filogenéticas também é um problema de projeto de redes.

A maioria dos problemas de projeto de redes são NP-difíceis [32][33]. Entretanto, muitos desses problemas estão presentes no mundo real e, portanto, soluções adequadas precisam ser encontradas. Nesse sentido, técnicas alternativas começaram a ser investigadas como, dentre elas, grande ênfase têm sido dada a investigação de Algoritmos Evolutivos (AEs) para esses problemas. No entanto, uma questão principal afeta o desempenho dos AEs em problemas com grafos: a codificação dos grafos na forma de cromossomo.

A codificação convencional dos cromossomos em AEs tem demonstrado ser ineficiente para problemas envolvendo grafos. Essa questão se torna mais grave quando a escala do sistema considerado (tamanho do grafo) é muito grande. Nesse sentido, recentemente novas estruturas de grafos para AEs aplicados a projeto de redes têm sido desenvolvidas [27][30][33]][35][36][37][38][39]. Dentre essas destacam-se a proposta de Delbem [35], denominada representação nó-profundidade (RNP), que tem demonstrado desempenho superior para o conjunto de problemas de projeto de redes utilizados para avaliação.

Nesse sentido, este trabalho propõe o desenvolvimento de um AE baseado na RNP para a construção de árvores filogenéticas, buscando uma alternativa ao algoritmo de busca exaustiva para obtenção de melhores árvores para definir a ordem dos pares de seqüências em multialinhamento progressivo. A Seção 5.2.2 apresenta codificação RNP. A Seção 5.2.3 propõe uma codificação específica para árvores filogenéticas baseada na RNP. 


\subsubsection{Representação nó-profundidade}

A RNP gera florestas de varredura que permitem representar árvores com componentes conectados e grafos acíclicos. Além disso, permite que o grau de diferença entre árvores pais e filhos seja controlável. Essa representação consiste de listas lineares contendo os nós das árvores e a sua profundidade. A ordem que os pares (nó, profundidade) são dispostas na lista é importante e depende da posição do nó em uma representação intermediária que utilize um tipo especial de seqüência de grafo. A ordem dos pares na RNP pode ser obtida por um algoritmo de busca em profundidade a partir do nó considerado como raiz da árvore. A cada nó visitado, a busca imprime o nó e sua profundidade gerando as duas listas lineares da representação, em geral, implementadas por arrays.

A codificação nó-profundidade apresenta dois operadores bastante similares para gerar novas florestas, denominados operador 1 e operador 2. Estes operadores produzem novas florestas geradoras Fo de um grafo $G$ quando aplicadas a outra floresta $F$ de $G$. Ambos os operadores transferem uma sub-árvore de uma árvore $T_{d e}$ (árvore origem) para $T_{\text {para }}$ (árvore destino). Enquanto que no operador 1 a raiz da sub-árvore podada é a mesma em $T_{d e} \mathrm{e}$ $T_{\text {para, }}$ no operador 2 , um novo nó (diferente da raiz) é escolhido para ser a nova raiz da subárvore em $T_{\text {para. }}$ O operador 1 considera dois nós em especial: o nó $p$, que indica a raiz da sub-árvore a ser transferida e o nó adjacente $a$, que não pertence a $T_{d e}$ mas é adjacente a $p$. O operador 2 requer além desses dois nós, o nó $r$ que será a nova raiz da sub-árvore.

\subsubsection{Operador 1}

Assuma que os nós $p$ e $a$ foram previamente escolhidos e a implementação da codificação utiliza arrays. Considere também como conhecidos os índices de $p\left(i_{p}\right)$ e a $(i a)$ nos arrays $T_{d e}$ e $T_{\text {para. }}$ O operador 1 pode ser descrito abaixo: 
1: Determine o intervalo $\left(i_{p}-i l\right)$ de índices em $T_{d e}$ correspondente à sub-árvore enraizada pelo nó $p$. Encontre $i$;

2: Copie os dados do intervalo $(i p-i l)$ de $T_{d e}$ em um array temporário $T_{T e m p}$;

3: Crie um array $T_{\text {para }}^{\prime}$ contendo os nós de $T_{p a r a}$ e de $T_{T e m p}$ (isto é, gere uma nova árvore conectando a sub-árvore podada a $\left.T_{p a r a}\right)$;

4: Construa um array $T^{\prime} d e$ compreendendo os nós de $T_{d e}$ sem os nós de $T_{T e m p}$;

5: Copie $F$ para $F_{0}$ mudando o ponteiro de $T_{d e}$ para $T^{\prime} d e$ e de $T_{p a r a}$ para $T_{\text {para }}^{\prime}$;

\subsubsection{Operador 2}

O operador 2 necessita a consideração de três nós para a descrição do algoritmo: o nó a ser podado $(p)$, a nova raiz $(r)$ e o nó adjacente $(a)$. Os nós $p$ e $r$ pertencem a Tde e o nó $a$ está em Tpara. As diferenças entre os operadores 1 e 2 estão nos passos 2 e 3, ou seja, somente a formação e armazenamento das sub-árvores podadas em arrays temporários são diferentes.

Para o operador 2, o procedimento de cópia da sub-árvore podada pode ser definido por dois passos. O primeiro passo é similar ao passo 2 do operador 1 . Ao invés de ser ip, considera-se ir. O array retornado por esse procedimento é denominado Ttemp1. O segundo passo considera os nós na cadeia de $r$ a $p$ (isto é, $r_{0}, r_{1}, r_{2}, \ldots, r_{n}$, onde $r_{0}=r$ e $r_{n}$ $=p$ ) como raízes de sub-árvores. A sub-árvore enraizada por $r_{l}$ contém a sub-árvore enraizada por $r_{0}$. A sub-árvore enraizada por $r_{2}$ contém a sub-árvore enraizada por $r_{1} \mathrm{e}$ assim por diante. O algoritmo para o segundo passo copia as sub-árvores enraizadas por $r_{i}$, onde $i=1, \ldots, n$, sem copiar a sub-árvore enraizada por $r_{i-1}$ e armazena as sub-árvores em um array temporário Ttemp2. 
No passo 3 do operador 2, ao invés de T'para ser criado a partir de Tpara e Ttemp, como no passo 3 do operador 1, T'para é construído utilizando os arrays Tpara, Ttempl e Ttemp2. Deve-se observar que esses operadores sempre produzem novas soluções factíveis sem a necessidade de algoritmos de reparo ou de verificação de ciclos. Algoritmos eficientes para determinação dos nós $p, r$ e a apropriados são apresentados em [35]. Os operadores 1 e 2 requerem tempo $O(\mid$ Tde $|+|$ Tpara $\mid+f)$ onde $\mid$ Ti $\mid$ indica o número de nós de $T i$ e $f$ é o número de árvores da floresta.

Os operadores 1 e 2 requerem florestas com pelo menos duas árvores. Entretanto, é possível utilizar os mesmos operadores para florestas com apenas uma árvore. Primeiramente, adiciona-se um árvore auxiliar Taux contendo somente um nó na floresta original com uma árvore (chamada Tuniq). Em seguida, a aplicação dos operadores 1 (2), dados $p$ e $a$ ( $p, r$ e $a$ ) é dividida em dois passos. Inicialmente, o operador 1 é utilizado para transferir a sub-árvore podada para a árvore auxiliar Tpara = Taux. usando o nó a igual ao único nó em Taux. Depois, aplica-se o operador 1 (2) para transferir a sub-árvore de Taux (Tde) para a árvore Tuniq $=$ Tpara .

\subsubsection{Adaptação da RNP para filogenias}

Foram necessárias 3 alterações no funcionamento da codificação nó-profundidade para que esta pudesse trabalhar adequadamente com árvores filogenéticas. Estas alterações atentam para a manutenção da integridade da árvore, que deve sempre possuir nós com grau igual a 3 (nó internos) ou 1 (nó folha). Além disso, na aplicação dos operadores, onde havia mais de uma possível implementação procurou-se utilizar aquela que causava menores alterações aos indivíduos, quando observadas as relações de similaridade entre indivíduos do mesmo clado. 
A saber, as alterações:
1) recorte;
2) reinserção;
3) matriz pi.

Ambos os operadores 1 e 2 extraem sub-árvores durante sua execução. No caso de uma árvore filogenética, o resultado de uma remoção descuidada seria um nó com grau 2.

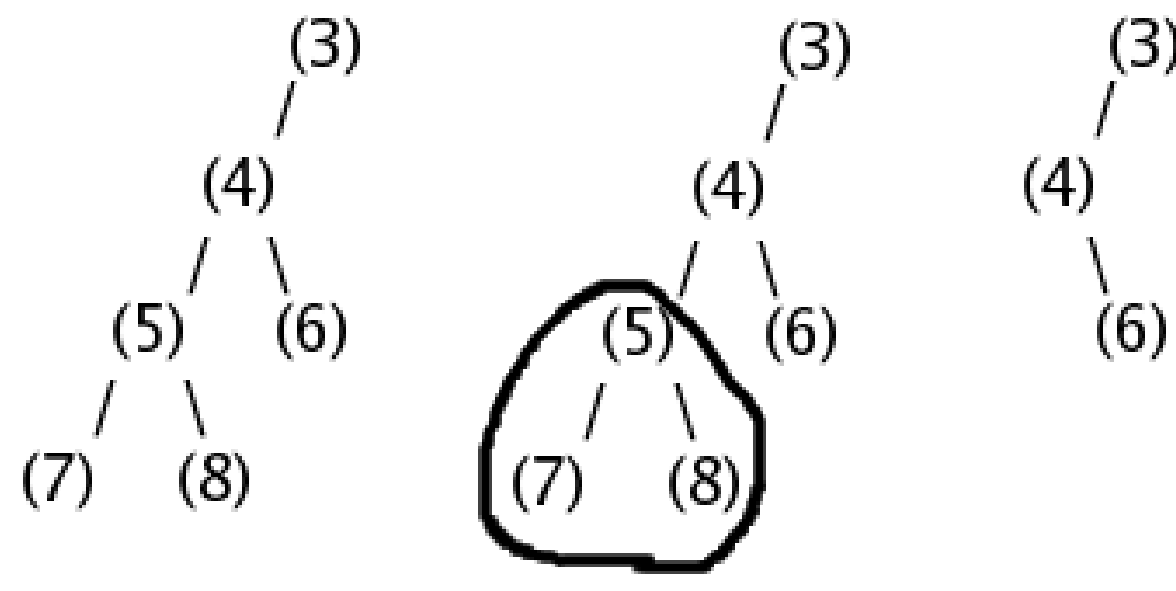

Figura 10: Remoção da sub-árvore de raiz 5 (em destaque) deixando nó 4 com grau 2.

Neste caso deve-se manter o nó interno 4 juntamente com a sub-árvore extraída. Com isso o nó 6 permanece como nó folha e como descendente de 3, mas passando a apresentar uma descendência direta.

A reinserção desta sub-árvore apresenta uma restrição. $O$ ponto de reinserção (nó destino) deve ser uma folha. Caso seja escolhido um nó interno, deve-se ou vasculhar entre seus nós até encontrar uma folha ou sortear outro. Após escolhido o destino, este é retirado e movido para a sub-árvore como segundo filho da raiz. Por sua vez, a nova sub-árvore é inserida onde antes estava o nó destino.

No resultado final os nós 4, 5, 7 e 8 continuam apresentando uma similaridade entre si. $\mathrm{O}$ 
nó 6 do exemplo anterior também mantém sua relação de similaridade com o nó 3.

Uma alternativa a essa forma de inserção seria simplesmente intercambiar o nó 13 com a sub-árvore de raiz 5. Entretanto uma alteração desse tipo alteraria bruscamente ambas as partes deslocadas. Como a intenção dos operadores é produzir pequenas mudanças que possam ser combinadas para se gerar mudanças mais profundas, optou-se pela forma apresentada inicialmente. Para tanto é preciso observar a extração e a inserção de subárvores com especial atenção à integridade da árvore.

Uma outra forma de se enxergar essa preocupação é pensar que os operadores devem procurar explorar novas relações entre os nós folha e não entre seus nós internos.

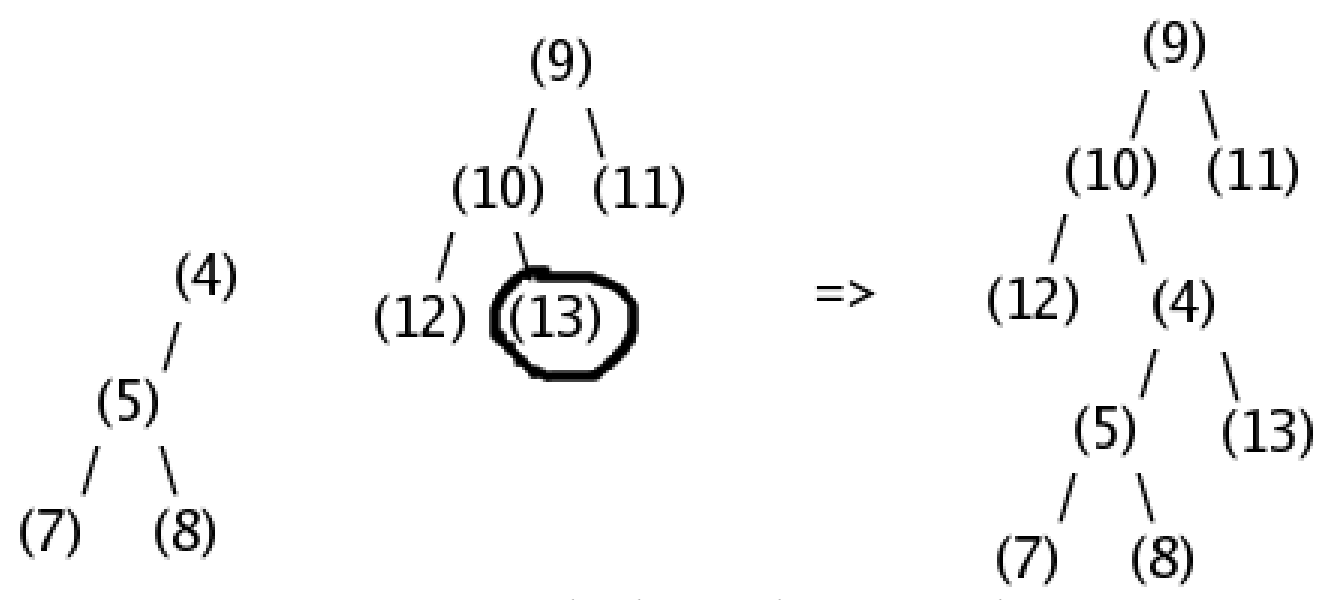

Figura 11: Inserção da sub-árvore de raiz 4 no nó destino 13.

A matriz pi era originalmente utilizada como forma de localização rápida de um nó, obtendo a árvore dentro da floresta e a posição dentro da árvore onde este se encontraria. Esta localização é necessária durante a utilização dos operadores 1 e 2 . No caso de árvores filogenéticas, estes operadores são utilizados como operadores de mutação e, como tal, só permitem trocas de nós apenas dentro da mesma árvore. Sendo assim a utilização da matriz pi foi substituída pela simples verificação de adjacências. 


\section{CONCLUSÕES}

O multialinhamento de seqüências é um problema computacionalmente complexo e muito importante para diversas tarefas em pesquisas biológicas e bioinfomática. Assim, técnicas capazes de produzir melhores alinhamentos ou que os produzem utilizando menos recursos computacionais são contribuições muito relevantes nessas áreas. Neste contexto, os algoritmos de multialinhamento progressivos têm apresentado resultados relativamente superiores na literatura. Os algoritmos progressivos em geral requerem um heurística eficiente para guiá-los em escolhas locais no processo de construção da solução para o problema. Desta forma, a eficiência de tais abordagens é extremamente dependente de tais heurísticas, que tendem direcionar a solução para ótimos locais.

Recentemente, abordagens iterativas baseadas em computação evolutiva têm mostrado resultados significativos. A utilização de algoritmos iterativos para multialinhamento, como os algoritmos genéticos que possuem um forte componente estocástico, é muito interessante, uma vez que tais algoritmos têm uma capacidade muito alta de superar ótimos locais para atingir soluções ainda melhores. Neste sentido, este trabalho buscou explorar a potencialidade do algoritmo SAGA. Apesar dos resultados descritos na literatura, o desempenho do algoritmo não foi similar para conjuntos de seqüências utilizados.

Pode-se dizer que este problema é computacionalmente muito complexo com um espaço de busca extremamente vasto. Assim, mesmo algoritmos iterativos com SAGA precisariam de heurísticas para guiá-los no processo de busca. Por outro lado, a inclusão de heurísticas adicionais no SAGA ou outro algoritmo evolutivo não é possível de ser obtida de forma efetiva. Uma heurística poderia ser a inclusão em cromossomos de trechos de seqüências multialinhadas por um algoritmo progressivo. Por exemplo, o próprio alinhamento, ou trechos desse, produzido pelo ClustalW poderia ser utilizado para alterar cromossomos. No 
entanto, esse tipo de procedimento, ao invés de aumentar a qualidade do alinhamento, em geral, diminui a sua qualidade pois, para realizar tais inclusões, o número de gaps aumenta muito.

Um amplo estudo foi realizado sobre a teoria de self organized criticality, uma vez que estudos da literatura indicam que algoritmos evolutivos baseados nesta teoria podem conseguir um aumento de desempenho muito significativo para problemas complexos como de multialinhamento de seqüências. Tais estudos permitiram organizar e obter conclusões interessantes sobre esta área da literatura. Acredita-se que este estudo, sintetizado no Apêndice, possa contribuir como uma revisão de literatura nesta área, buscando esclarecer resultados controversos e norteando novas pesquisas na área.

Diante do relativamente baixo desempenho obtido com os algoritmos evolutivos para o problema de multialinhamento, o foco da pesquisa foi direcionado para investigação das estratégias progressivas. Nesta etapa foi investigado o algoritmo ClustalW. Uma das principais heurísticas utilizadas pelo ClustalW é o emprego de árvores guia. Como essas têm sido obtidas por algoritmos de busca local e o problema de construção de árvores filogenéticas é também computacionalmente complexo, a possibilidade de existirem árvores que poderiam guiar melhor o multialinhamento era relativamente alta. As pesquisas, então, seguiram duas etapas. A primeira foi a verificação da existência de melhores árvores guia mesmo para problemas menores, envolvendo conjuntos relativamente pequenos de seqüências curtas. A segunda etapa foi a avaliação da contribuição de melhores árvores guia para o processo de multialinhamento. Nessa etapa utilizou-se os dados do BAliBASE, que fornece uma ampla e, biologicamente selecionados, conjuntos de seqüências disponibilizados para avaliação de procedimentos de alinhamento. Os resultados mostraram 
que a abordagem proposta consegue obter resultados melhores do que o algoritmo ClustalW utilizando a heurística de árvores guia obtida pelo neighbor-joining.

A abordagem proposta é computacionalmente custosa para grandes conjuntos de seqüências longas, uma vez que a obtenção de árvores guias melhores pode requerer a busca por todo o espaço de topologias de árvores para um certo conjunto de seqüências. Diante deste fato, a pesquisa foi então direcionada para a investigação de formas computacionalmente mais eficientes para explorar o espaço de busca por topologias melhores. O problema de encontrar uma árvore filogenética como guia pode ser visto como um problema de projeto de redes. Problemas desse tipo são uma área da otimização combinatória, que pesquisa por algoritmos mais eficientes para resolver problemas que envolvem desde de redes de telecomunicações a roteamento de veículos. Existem algoritmos evolutivos relativamente bem desenvolvidos para projeto de redes, ou seja, é possível explorar o espaço de busca adequadamente e evitar ótimos locais em direção a soluções melhores.

Neste trabalho, estudou-se as metodologias de algoritmos evolutivos para projeto de redes. Com base neste estudo, optou-se por utilizar a técnica evolutiva baseada na Representação Nó-profundidade de grafos. A partir desta técnica, foi proposto um procedimento para buscar por árvores filogenéticas guia de forma mais eficiente. A implementação desta metodologia e sua validação é um projeto de pesquisa extenso e deve ser realizado em trabalho futuro.

Por fim, pode-se dizer que diversos aspectos relevantes dos algoritmos para multialinhamento de seqüências foram investigados. Contribuições relevantes foram apresentadas, além de uma proposta com perspectivas para melhoras ainda mais 
significativas para esta área. 


\section{Referências}

1 Mount, D. W.,2001.Bioinformatics: Sequence and Genome Analysis.Cold Spring Harbor Laboratory Press.

2 Hanada, K., Yokoyama, T., Shimizu, T., 2000. Multiple Sequence Alignment by Genetic Algorithm. Genome Informatics, 11.

3 Isokawa, M., Wayama, M., Shimizu, T., 1996. Multiple Sequence Alignment Using a Genetic Algorithm. Genome Informatics, 7.

4 Harada, Y., Wayama, M., Shimizu, T., 1997. An Inspection of the Multiple Alignment Method with use of a GA. Genome Informatics, 8.

5 Yokoyama, T., Watanabe, T., Taneda, A., Shimizu, T., 2001. A Web Server From Multiple Sequence Alignment Using Genetic Algorithm. Genome Informatics, 12.

6 Notedrame, C., Higgins, D. G., 1996. SAGA: Sequence Alignment by Genetic Algorithm. Nucleic Acids Research, 24.

7 Fogel, G. B. e Corne, D. W.,2003.Evolutionary Computation In Bioinformatics.Morgan Kaufmann Publishers.

8 Watson, J. D. e Crick, F. H. C., 1953. Molecular Structure Of Nucleic Acids. Nature.

9 Setúbal, J. e Meidanis, J.,1997.Introduction to Computational Biology.PWS Publishing Company.

10 Voet, D., Voet, J. G., Pratt, C. W.,2002.Fundamentos de Bioquímica. Artmed Editora. 11 Karadimitrou, K. e Kraft, D. H., 1996. . Proc. Second Annual Mol. Biol. and Biotech. Conf..

12 Fogel, D.,1995. Evolutionary Computation. IEEE Press.

13 Ridley, M.,1996.Evolution. Blackwell Science INC.

14 Klug, W. S., Cummings, M. R.,1997.Concepts of Genetics.Prentice Hall.

15 Darwin, C.,2000.A Origem das Espécies e a Seleção Natural. Hemus S.A..

16 Mitchell, M.,1999.An Introduction to Genetic Algorithms.MIT Press.

17 Monard, M. C., Batista, G. E. A. P. A., Kawamoto, S., Pugliesi, J. B., 1997. Uma introdução ao Aprendizado Simbólico de Máquina por Exemplos. .

18 Gen, M., Cheng, R.,1997.Genetic Algorithms and Engineering Design. John Willey \& Sons, INC.. 
19 Goldberg, D. E.,1989.Genetic Algorithm in Search, Optimization, and Machine Learning.Addison-Wesley Publishing Company INC..

20 Mitchell, T. M.,1997.Machine Learning. McGraw-Hill.

21 Gibas, C. e Jambeck, P., 2001.Developing Bioinformatics Computer Skills.O'Reilly \& Associates, Inc..

22 Notredame, C., 2002. Recent Progress In Multiple Sequence Alignment: A Survey. Pharmacogenomics, 3 .

23 Baxevanis, A. D., Ouellette, B. F. F.,2001.Bioinformatics. John Wiley \& Sons, Inc..

24 Wayama, M., Takahashi, K., Shimitzu, T., 1995. An Approach to Amino Acid Sequence Alignment Using a Genetic Algorithm. Genomic Informatics Workshop 1995.

25 Fogel, G. B. e Corne, D. W., 2003. Evolutionary Computation In Bioinformatics . Morgan Kaufmann Publishers.

26 Crescenzi, P.; Kann,V., 2005. A Compendium of NP Optimization Problems. url http://www.nada.kth.se/ viggo/problemlist/ - Acessado em 02/2006.

27 Palmer, C., Kershenbaum, A., 1995. An approach to a problem in network design using genetic algorithms. Networks 26, 101-107.

28 Chou, H.H., Premkumar, G., Chu, C.H., 2001. Genetic algorithms for communications network design - an empirical study of the factors that influence performance. IEEE Transactions on Evolutionary Computation 5, 236-249(3).

29 Harary, H.; Gupta, G., 1997. Dynamic Graph Models. Mathl. Comput. Modelling, 25:79-87.

30 Zhou, G., Gen, M., 2003. A genetic algorithm approach on tree-like telecommunication network design problem. J. of the Operational Research Society 54.

31 Reijmers, T. H.; Wehrens, R.; Daeyaert, F. D.; Lewi, P. J.; Buydens L. M. C. 1999. Using Genetic Algorithm for the Construction of Phylogenetic Trees: Application to gprotein Coupled Receptor Sequences. Biosystem 49, 31-43.

32 Gen, M., Cheng, R., 1997. Genetic Algorithms and Engineering Design. Ashikaga Institute of Technology, Ashikaga, Japan.

33 Knowles, J., Corne, D., 2000. A new evolutionary approach to the degreeconstrained minimum spanning tree problem. IEEE Transaction on Evolutionary Computation 4 125-134(2). 
34 Sipser, M., 1997. Introduction to the Theory of Computation. PWS Publishing Company, Boston.

35 Delbem, A.C.B., de Carvalho, A., Policastro, C.A., Pinto, A.K.O., Honda, K., Garcia, A.C.: Node-depth encoding applied to the network design. Genetic Algorithm and Evolutionary Computation Conference 20003, Lecture Notes in Computer Science 3102 (2004) 678-687.

36 Langdon, W.B.: Genetic Programming and Data Structures. Kluwer Academic Pub (1998).

37 Rothlauf, F., Goldberg, D.E., Heinzl, A., 2000. Network random keys - a tree network representation scheme for genetic evolutionary algorithms. Evolutionary Computation 20 (2), 75-97.

38 Carvalho, P.M.S., Ferreira, L.A.F.M., Barruncho, L.M.F., 2001. On spanning tree recombination in evolutionary large-scale network problems - application to elec- trical distribution planning. IEEE Transactions on Evolutionary Computation 5, 623-630(6).

39 Raidl, G.R., Julstrom, B.A., 2003. Edge sets: an effective evolutionary coding of spanning trees. IEEE Trans. Evolutionary Computation 7, 225-239.

40 Thomson, J.D., Plewniak, F., Poch, O., 1999, BAliBASE: a benchmark alignment database for the evaluation of multiple alignment programs, Bioinformatics, 15

41 Felsenstein, J., PHYLIP---Phylogeny Inference Program, url http://evolution.genetics.washington.edu/phylip/phylip.html. Acessado em 02/2006 


\section{APÊNDICE}

\section{O que é self-organized criticality?}

Conhecer detalhadamente partes de um sistema complexo não implica necessariamente que se pode dominar o funcionamento do sistema como um todo. Um exemplo disso é o conhecimento da gravitação newtoniana. Pode-se estudar com precisão o comportamento de dois corpos, mas se um terceiro corpo for adicionado ao sistema, este se torna insolúvel analiticamente.

Sistemas complexos apresentam propagação de interações entre seus elementos, que não podem ser decompostos e estudados separadamente. Ao se estudar a relação entre as variáveis que descrevem estas interações, observa-se um comportamento que independe da escala utilizada, que ocorre quando o sistema se aproxima de um estado estacionário (longe do equilíbrio) no limiar entre duas fases. Este ponto característico é conhecido por ponto crítico. Quando o sistema o atinge sem ajustes em parâmetros extras, este ponto é chamado de ponto crítico auto-organizado (SOC). Uma propriedade deste ponto é sua atuação como um atrator do sistema. Independente das condições iniciais, este ponto é sempre alcançado [1], [2] e [3].

Artigo inicial foi de autoria de Bak Tang Weisenfeld (BTW) que apresentava como modelos o sandpile model, forest fire model e earthquake model. Todos são autômatos celulares motivados por sistemas físicos reais.

BTW apresentaram o SOC como explicação para um padrão ubíqüo em sistemas reais: espectro de potência $1 / f$, também conhecido como ruído $1 / f$. Este espectro está relacionado com estruturas fractais [1], [2] e [3]. O SOC foi proposto como explicação para a universalidade deste espectro e poderia produzir um ruído $1 / f$. Entretanto estudos posteriores mostraram que o ruído gerado pelo SOC era na verdade $1 / \mathrm{f}^{2}[3]$. 


\section{Que mecanismo cria o SOC?}

Interações locais entre componentes de um sistema aberto podem apresentar características emergentes. Estas interações normalmente afetam apenas a vizinhança do ponto inicial. Entretanto, em alguns casos, a interação expande-se para além da região inicial. A freqüência com que isso ocorre e sua amplitude apresentam uma relação: quanto maior a amplitude, menos freqüente é o evento, e vice-versa. Essa relação, também conhecida por ruído $1 / f$, apresenta um comportamento que é invariante no tempo. Ou seja, não importa a escala de tempo que se observe o sistema, a relação mantém-se constante [2].

Quando um sistema aberto está em um estado crítico (SOC), em média a quantidade de partículas que entram é a mesma que a perdida pelo sistema.

Um modelo que tenta simular este comportamento é o "sandpile model" (SM) [2].

\section{Qual a relação com um AE?}

Imagens de paisagens geológicas podem ser pouco úteis se não houver em sua proximidade um objeto de escala conhecida. Este é um exemplo de um padrão independente da escala. Uma hipótese que poderia explicar a semelhança entre cenários de escala tão diferentes é a presença de processos que também atuariam em várias escalas. No exemplo, a erosão e sedimentação seriam agentes ativos na definição da forma tanto de um pequeno acidente geográfico quanto de um de grandes extensões. Terremotos apresentam uma distribuição de ocorrências no decorrer do tempo que independe da intensidade. Com isso pode-se inferir que tanto pequenos quanto grandes tremores estariam sujeitos ao mesmo mecanismo. Sendo assim, descartar pequenos tremores ao se tentar fazer algum tipo de previsão seria descartar dados que fazem parte do sistema como um todo [4].

Sistemas complexos tornam-se invariantes no tempo quando estes se aproximam de uma 
transição de fase. A passagem da água do estado líquido para vapor, sob certas circunstâncias bem específicas, causa o aparecimento de um estado chamado de crítico, onde líqüido e vapor coexistem, e certos atributos estatísticos passam a apresentar um comportamento característico. Esse conhecimento se extende a alguns sistemas complexos, chamados de críticos [4].

A análise de registros fósseis sugere um padrão semelhante na ocorrência das extinções. Fica a questão sobre a existência de criticalidade em sistemas biológicos [1], [4].

No trabalho [1], uma série de números gerados pelo modelo SM controlou a taxa de mutação de um cromossomo com genes constituídos de números reais. Esta série também foi utilizada como multiplicador do operador de mutação, que já utilizava uma distribuição gaussiana como peso. Em comparações com o algoritmo evolutivo (EA) clássico, o SOCEA teve um desempenho final melhor na maioria dos casos a um custo de $3 \%(20 \% \mathrm{em}$ [2])) no tempo de execução, apesar de apresentar no início das iterações uma convergência mais lenta [1].

Uma variação do procedimento foi criar indivíduos novos (migrantes) ao invés de mutar os existentes, na ocorrência de extinções. Entretanto esta mudança mostrou um desempenho melhor apenas em um dos seis casos estudados. Outra variação estudada foi a política de substituição da população. Substituir os melhores ou piores indivíduos não mostrou melhorias no resultado, apesar de aumentar seu custo computacional [1].

\section{Por que funciona?}

SOC, na implementação apresentada no artigo, combina duas tendências. A nova mutação é responsável pelo espalhamento de indivíduos pelo espaço de busca. A extinção força a população a se ater apenas à regiões mais promissoras. Além destes fatores, a 
mutação utilizar uma variação de distribuição gaussiana em conjunto com o elitismo, também foram importantes na realização dos testes [1].

Um AE típico normalmente apresenta uma convergência prematura, resultado de uma perda de variação genética na população. SOC lida com esse problema ao ocasionalmente inserir novos indivíduos na população.

\section{Sandpile Model}

O objetivo deste modelo é gerar um vetor de números que representam a intensidade de um evento (no caso, uma avalanche) em um instante de tempo discreto. Ao se analisar o espectro de potência deste vetor freqüências de avalanches, observa-se uma distribuição 'power law'.

Seja uma matriz $d$-dimensional de números inteiros não negativos. Estes números representam a quantidade de partículas empilhadas em cada posição. No estado inicial da matriz, todas as suas posições contém o número zero representando uma posição vazio.

O processo de geração de números inicia-se com a escolha aleatória de uma posição, sobre a qual será depositada uma partícula. Se a altura da pilha ultrapassar um valor-limiar, diz-se que a posição encontra-se instável. Neste ponto inicia-se um processo (avalanche) que irá causar o retorno da posição à estabilidade.

Ao atingir a instabilidade, a posição-alvo tem seu valor reduzido e as posições vizinhas são incrementadas de forma que a soma das partículas seja mantida constante, em um deslocamento conservativo. Se nesta atualização algum dos vizinhos tornar-se instável, o processo é repetido de forma recursiva.

Dessa forma o vetor de números é construído. A cada partícula incluída na matriz, anota-se a intensidade da avalanche criada. Por intensidade entende-se a quantidade de 
posições que atingiram a altura crítica. Na maior parte dos casos, não haverá avalanches. Eventos pequenos serão freqüentes e os de maior intensidade serão cada vez mais raros.

Durante as avalanches, as adições são suspensas. Estas voltam a ocorrer apenas quando todas as posições foram atualizadas. Também durante este processo, as bordas da matriz perderão partículas quando posições marginais atingirem a altura crítica e parte das partículas deixarem a matriz. Estas duas características são os fatores decisivos para que o modelo atinja o estado de auto-organização [3].

O processo continua e um estado estatisticamente estacionário é atingido, no qual a quantidade de partículas adicionadas é igual, em média, à quantidade de partículas perdidas pelas bordas. Este é o estado crítico auto-organizado [3].

Utilizando o SM é criado um vetor de números que seguem uma distribuição do tipo 'power law'. Utiliza-se cada posição do vetor, seguindo-o de forma seqüencial, como parâmetro na mutação e na extinção em massa na população. Dessa forma a freqüência destes eventos seguirá um padrão semelhante ao que ocorre na natureza [2]. 


\section{REFERÊNCIAS}

[1] Krink, T., Thomsen, R., Rickers, P., 2000. Applying Self-Organised Criticality to Evolutionary Algorithms. Parallel Problem Solving from Nature -- PPSN VI, vol. 1, p. $375-$ 384

[2] Krink, T., Thomsen, R., 2001. Self-Organized Criticality and Mass Extinction in Evolutionary Algorithms. Proceedings of the Third Congress on Evolutionary Computation (CEC-2001) vol. 2, p. 1151-1161

[3] Kienert, J., 1998. Self-Organized Criticality. Disponível em: Citeseer <citeseer.ist.psu.edu/kienert98selforganized.html> Acesso em: 02 set. 2005.

[4] Gisiger, T., 2001. Scale Invariance in Biology: Coincidence or Footprint of a Universal Mechanism? Biol. Rev. vol. 76, p. 161-209.

[5] Baiesi, M, Maes, C., 2005. Realistic time correlations in self-organized criticality from a random walk driving. Disponível em: Citebase Search $<\underline{\text { http://arxiv.org/abs/cond- }}$ mat/0505274> Acesso em: 02 set. 2005.

[6] Goldenfeld, N., Kadanoff, L. P., 1999. Simple Lessons from Complexity. Science vol. 284 , p. $287-289$

[7] Woodard, R., Newman, D. E., Sánchez, R., Carreras, B. A., Building blocks of selforganized criticality. Disponível em: Citebase Search $<\underline{\text { http://arxiv.org/abs/cond- }}$ mat/0503159> Acesso em: 02 set. 2005. 